\title{
Vertical redistribution of moisture and aerosol in orographic mixed-phase clouds
}

\author{
Annette K. Miltenberger ${ }^{1,2}$, Paul R. Field ${ }^{1,3}$, Adrian H. Hill ${ }^{3}$, and Andrew J. Heymsfield ${ }^{4}$ \\ ${ }^{1}$ Institute of Climate and Atmospheric Science, School of Earth and Environment, University of Leeds, Leeds, UK \\ ${ }^{2}$ Institute for Atmospheric Physics, Johannes Gutenberg University Mainz, Mainz, Germany \\ ${ }^{3}$ Met Office, Exeter, UK \\ ${ }^{4}$ National Center for Atmospheric Research, Boulder, Colorado, USA
}

Correspondence: Annette K. Miltenberger (amiltenb@uni-mainz.de)

Received: 14 October 2019 - Discussion started: 20 January 2020

Revised: 27 April 2020 - Accepted: 10 June 2020 - Published: 10 July 2020

\begin{abstract}
Orographic wave clouds offer a natural laboratory to investigate cloud microphysical processes and their representation in atmospheric models. Wave clouds impact the larger-scale flow by the vertical redistribution of moisture and aerosol. Here we use detailed cloud microphysical observations from the Ice in Clouds Experiment - Layer Clouds (ICE-L) campaign to evaluate the recently developed Cloud Aerosol Interacting Microphysics (CASIM) module in the Met Office Unified Model (UM) with a particular focus on different parameterizations for heterogeneous freezing. Modelled and observed thermodynamic and microphysical properties agree very well (deviation of air temperature $<1 \mathrm{~K}$; specific humidity $<0.2 \mathrm{~g} \mathrm{~kg}^{-1}$; vertical velocity $<1 \mathrm{~m} \mathrm{~s}^{-1}$; cloud droplet number concentration $<40 \mathrm{~cm}^{-3}$ ), with the exception of an overestimated total condensate content and too long a sedimentation tail. The accurate reproduction of the environmental thermodynamic and dynamical wave structure enables the model to reproduce the right cloud in the right place and at the right time. All heterogeneous freezing parameterizations except Atkinson et al. (2013) perform reasonably well, with the best agreement in terms of the temperature dependency of ice crystal number concentrations for the parameterizations of DeMott et al. (2010) and Tobo et al. (2013). The novel capabilities of CASIM allowed testing of the impact of assuming different soluble fractions of dust particles on immersion freezing, but this is found to only have a minor impact on hydrometeor mass and number concentrations.

The simulations were further used to quantify the modification of moisture and aerosol profiles by the wave cloud.
\end{abstract}

The changes in both variables are on order of $15 \%$ of their upstream values, but the modifications have very different vertical structures for the two variables. Using a large number of idealized simulations we investigate how the induced changes depend on the wave period (100-1800 s), cloud top temperature $\left(-15\right.$ to $\left.-50^{\circ} \mathrm{C}\right)$, and cloud thickness $(1-5 \mathrm{~km})$ and propose a conceptual model to describe these dependencies.

Copyright statement. The works published in this journal are distributed under the Creative Commons Attribution 4.0 License. This license does not affect the Crown copyright work, which is reusable under the Open Government Licence (OGL). The Creative Commons Attribution 4.0 License and the OGL are interoperable and do not conflict with, reduce or limit each other.

(C) Crown copyright 2020

\section{Introduction}

The advent of (sub-)kilometre-scale numerical weather prediction models in recent years has strongly improved the prediction of clouds and precipitation (e.g. Clark et al., 2016). However, simplification in the representation of cloud microphysical processes and incomplete physical understanding of some key processes result in fairly large uncertainties in the representation of individual cloud microphysical processes, which also impact the macroscopic appearance of clouds, precipitation formation and cloud evolution (e.g. Muhlbauer 
et al., 2010; Johnson et al., 2015). To improve the representation of cloud microphysical processes and to reduce the associated uncertainty, the combination of model simulations with detailed observational data from dedicated field campaigns is of fundamental importance alongside the careful investigation of individual processes in the laboratory. Clouds forming in laminar flow in the vicinity of significant topography, so-called orographic wave clouds, have been suggested as natural laboratories to investigate cloud processes under ambient atmospheric conditions (e.g. Heymsfield and Miloshevich, 1993; Field et al., 2001; Muhlbauer and Lohmann, 2009). In contrast to convective cloud fields, the quasistationary, laminar flow provides a well-constrained thermodynamic environment and dynamic forcing and allows for direct comparisons between observations and model results (e.g. Heymsfield and Miloshevich, 1993; Eidhammer et al., 2010; Field et al., 2012).

Orographic clouds known to be important for weather and climate, as they occur frequently in mountainous regions (e.g. Grubisic and Billings, 2008; Vosper et al., 2013), modify regional precipitation patterns (e.g. Sawyer, 1956; Smith et al., 2015) and influence radiative fluxes (e.g. Joos et al., 2008). Most studies on orographic clouds have focussed on their contribution to surface precipitation and its distribution, which has been investigated in a large number of idealized and realistic simulations with models of various complexity (e.g. Houze, 2012; Miltenberger et al., 2015; Henneberg et al., 2017). It has been shown that depending on the upstream conditions and the shape of the topography different cloud microphysical processes dominate the precipitation formation (e.g. Jiang and Smith, 2003; Colle and Zeng, 2004), and varying ambient aerosol concentrations can modify precipitation amounts and patterns (e.g. Muhlbauer et al., 2010; Zubler et al., 2011; Xiao et al., 2015). Precipitation formation results not only in a vertical redistribution of moisture but also a vertical transport of aerosol particles, which are incorporated into hydrometeors during cloud droplet or ice crystal nucleation (nucleation scavenging) or by aerosol-hydrometeor collisions (impaction scavenging) (e.g. Xue et al., 2012; Pousse-Nottelmann et al., 2015). However, not all aerosol particles incorporated into hydrometeors are removed to the surface, as a significant fraction of condensate evaporates before reaching the ground, and the associated aerosol particles are released upon evaporation (or sublimation) (e.g. Xue et al., 2012; Pousse-Nottelmann et al., 2015). This results in modifications of the vertical profile of aerosol number and also the aerosol chemical composition. These changes modify the precipitation formation in clouds that form later in the same air mass, although to a lesser extent than varying upstream humidity of aerosol number concentration (Xue et al., 2012).

While orographic clouds producing (large) amounts of precipitation are very relevant in socioeconomic terms, isolated wave clouds in the middle troposphere, which do not produce surface precipitation, are better suited to study the basic mixed-phase cloud processes of heterogeneous freezing, depositional growth, hydrometeor sedimentation, and aerosol transport. In contrast to thicker orographic clouds, the collision-coalescence process is less important, and the interactions between air parcels travelling through the clouds at different altitudes is minimal. Also, their smaller horizontal and vertical extent implies that representative observations are obtained more easily. One particular question, for which observations in isolated mid-tropospheric mixed-phase wave clouds has been instrumental, is the glaciation of clouds. The formation of ice in all mixed-phase clouds, not only orographic wave clouds, plays a crucial role for the efficiency of precipitation formation (as already pointed out in early studies by Bergeron, 1935 and Findeisen, 2015) and the cloud optical properties (e.g. Joos et al., 2014; Vergara-Temprado et al., 2018).

In the atmosphere ice forms either via homogeneous freezing of solution droplets at temperature colder than about $-35^{\circ} \mathrm{C}$ or at warmer temperatures through the mediation of certain aerosol particles, which are called ice-nucleating particles (INPs). INPs can trigger ice formation via different processes, including immersion, contact, and deposition freezing (e.g. Kanji et al., 2017). Aircraft observations in orographic wave clouds have demonstrated the large increase in ice crystal number concentration due to the onset of homogeneous freezing at cold cloud top temperatures. For example, Heymsfield and Miloshevich (1993) showed that ice crystal concentrations of $\sim 60 \mathrm{~cm}^{-3}$ observed at temperatures colder than $-35^{\circ} \mathrm{C}$ in wave clouds over the mountain states of the United States are consistent with parcel-model predictions assuming homogeneous freezing. Ice crystal concentrations at warmer temperatures were below the detection limit of the particle probes. Similarly, for wave clouds over Scandinavia Field et al. (2001) found homogeneous freezing to be dominant at temperatures colder than $-35^{\circ} \mathrm{C}$, while ice at warmer temperatures was most likely formed via immersion or contact nucleation, i.e. freezing mechanisms requiring INPs. Ice crystal number concentrations at these warmer temperatures has been observed to correlated with the presence of large aerosol particles (Baker and Lawson, 2006; Eidhammer et al., 2010) and chemical analysis of ice crystal residuals found predominantly mineral dust with some contributions from organics and salts, which are known to be efficient INPs (e.g. Targino et al., 2006; Pratt et al., 2010). Depending on whether INPs are incorporated before or during the freezing event, different heterogeneous freezing mechanisms are distinguished. In mixed-phase orographic clouds immersion freezing, i.e. INPs acting first as cloud condensation nuclei and later initiating the freezing of the cloud droplets, is likely the dominant freezing mechanism according to model-based (Hande and Hoose, 2017) analysis and comparison between parcel model simulations and observations (Field et al., 2001; Eidhammer et al., 2010). Deposition and contact freezing are likely not important. However, Cotton and Field (2002) could not completely recon- 
cile box-model simulations using known freezing mechanisms with observations of hydrometeor number concentrations and mass mixing ratios.

The representation of heterogeneous freezing in numerical models relies on empirical relationships involving aerosol number concentrations and temperatures, because the fundamental processes of the ice nucleation process and those determining the efficiency of specific aerosol particles to act as INP are not yet understood. Several empirical formulation of heterogeneous (immersion) freezing have been proposed: early parameterizations such as Fletcher (1958) or Meyers et al. (1992) are solely based on ambient air temperature, while later parameterizations additionally take into account the number concentration of large $(>0.5 \mu \mathrm{m})$ aerosol particles (e.g. DeMott et al., 2010, 2015; Tobo et al., 2013). The main difference between the latter parameterizations is the geographic regions, in which the underlying observations were made, and hence they likely represent different chemical and/or mineralogical compositions of the INP population. Other recent parameterizations use estimates of the temperature-dependent number of active sites on specific materials and the surface area of the aerosol population to predict the number of INPs at a given temperature (Niemand et al., 2012; Atkinson et al., 2013). Again the main difference between the parameterizations is the materials, for which the number of actives sites was determined. It is not clear how the different parameterizations affect cloud properties and whether the difference between the parameterizations can be directly assessed with observations of ice crystal number concentrations.

Previous work has demonstrated the usefulness of observations in orographic clouds to investigate cloud microphysical processes. However, detailed cloud microphysical analysis in models was limited to parcel, column, or idealized two-dimensional simulations. Here we use observations in isolated, midlevel wave clouds during the Ice in Clouds Experiment - Layer Clouds (ICE-L) campaign to assess the performance of the recently developed Cloud-Aerosol Interacting Module (CASIM) in three-dimensional simulations with Met Office Unified Model (UM), i.e. a nonhydrostatic model used for operational weather prediction. The objectives of the present work are in particular as follows:

- Is the numerical weather prediction model able to capture the thermodynamic conditions and wave cloud dynamics with sufficient accuracy, i.e. the right cloud in the right place at the right time, to allow for a direct comparison of cloud microphysical properties between model and observations?

- Can observations of the vertical variation in ice crystal number concentration be used to assess the validity of different heterogeneous freezing parameterizations?
- How large is the modification of the water vapour and aerosol profiles by the wave cloud? How does the downward transport of water vapour and aerosols depend on the upstream thermodynamic conditions? And under which conditions is the downward flux largest, i.e. can be best observed in future campaigns?

The analysis focusses on a wave cloud over the central United States probed with the National Science Foundation (NSF) C-130 aircraft (16 November 2007, RF03) during the Ice in Clouds Experiment - Layer Clouds (ICE-L) (Heymsfield et al., 2011; Pratt et al., 2010). Data from ICE-L have been used to investigate the relationship between upstream INP measurements and ice crystal number concentrations (Eidhammer et al., 2010; Field et al., 2012), the depositional growth of ice crystals (Heymsfield et al., 2011), and the impact of using adaptive ice crystal habits in idealized model simulations (Dearden et al., 2012). The chemical analysis of cloud droplet and ice crystal residuals by Pratt et al. (2010) indicated that INPs active in the observed wave clouds are most likely mineral dust internally mixed with a significant salt component, as may be expected from aerosols emitted from playas in the central United States.

Details on the observations, models, and their set-up are provided in the following section. In Sect. 3 we present the comparison of observed wave cloud properties to the results from high-resolution simulations with the Met Office UM with a specific focus on the vertical gradient in ice crystal number concentration (Sect. 3.3). A Lagrangian analysis of the simulations provides insight into the modification of humidity and aerosol profiles by the wave cloud (Sect. 4.1). The dependence of amplitude and shape of this modification on the gravity wave length and upstream thermodynamic conditions determining cloud top temperature and cloud thickness is assessed with additional idealized simulations in Sect. 4.2. Finally, Sect. 5 summarizes the results and discusses implications for future aircraft observations in orographic wave clouds to constrain mixed-phase cloud microphysics.

\section{Data and methods}

\subsection{Observational data from ICE-L}

We use data from various instruments on board the National Science Foundation (NSF) C-130 aircraft for information about aerosol, cloud, and ice populations in the mixed-phase clouds observed in RF03 of the ICE-L campaign. Details on the instrumentation can be found in Heymsfield et al. (2011) for hydrometeor and aerosol size distributions and Pratt et al. (2010) for the aerosol chemical composition. Here we focus on a wave cloud observed on 16 November 2007 (RF03), for which observations from three different altitudes are available within a time interval of roughly $40 \mathrm{~min}$. For the model evaluation, we use the King liquid water probe for total liquid water content, the 2D-C and the $2 \mathrm{D}-\mathrm{S}$ probe for ice num- 
ber concentrations and estimated ice water content, the CDP (cloud droplet probe) for cloud droplet number concentrations, the tuneable diode laser hygrometer (TDL) for humidity measurements, the counterflow virtual impactor (CVI) for total water content, and aerosol size distributions from the ultra-high sensitivity aerosol spectrometer (UHSAS) for size-resolved number concentrations. The data from 2D-C and 2D-S are restricted to particles larger than $50 \mu \mathrm{m}$. The small threshold particle size for the 2D-C is justified by the good agreement between ice crystal number concentrations from the 2D-S and 2D-C. Shattering in wave clouds is very likely not a large issue due to the predominantly small size of the ice crystals. As in Field et al. (2012) we correct the TDL humidity such that it is consistent with water saturation in the regions with a liquid water content (from the King liquid water probe) larger than $0.02 \mathrm{~g} \mathrm{~m}^{-3}$. Further details on the data and their postprocessing can be found in Field et al. (2012).

\subsection{The Unified Model}

We use the Unified Model (UM), the numerical weather prediction model developed by the Met Office and used for operational forecasting in the UK, to conduct simulations of the wave cloud observed during research flight 3 of the ICEL campaign (16 November 2007). A global simulation (UM vn10.8, GA6 configuration, N512 resolution; Walters et al., 2017) starting from the operational analysis at 12:00 UTC on 16 November 2007 provides the initial and lateral boundary conditions for regional model simulations. Two regional nests are used, the first with a horizontal grid spacing of $1 \mathrm{~km}$ and the second with a grid spacing of $250 \mathrm{~m}$. Both nests are centred at the location of the observed wave cloud $\left(42.12^{\circ} \mathrm{N},-105.10^{\circ} \mathrm{E}\right)$. The analysis presented in this paper focuses on the innermost nest. In the vertical we use a stretched vertical coordinate system with 140 levels, which provides a vertical resolution of $130-200 \mathrm{~m}$ at the altitude of the observed cloud. Mass conservation is enforced in the regional simulations (Aranami et al., 2014, 2015), and sub-grid-scale turbulent processes are represented with a 3D Smagorinsky-type turbulence scheme (Halliwell, 2015; Stratton et al., 2015). The cloud microphysics are represented with the Cloud-AeroSol Interacting Microphysics (CASIM) module (see Sect. 2.4). As we are particularly interested in the impact of ice-nucleating particles (INPs) in the cloud we conduct sensitivity experiments with different heterogeneous ice nucleation parameterizations as well as different assumptions regarding the incorporation of INPs into cloud droplets, which is prerequisite for immersion freezing. The details of these sensitivity experiments are described in Sect. 2.4.

\subsection{The KiD Model}

For the analysis of a large set of wave clouds we conduct additional idealized simulations with the Kinematic Driver Model (KiD, Shipway and Hill, 2012; Hill et al., 2015).
The KiD model uses prescribed dynamics to drive different microphysics modules and hence testing of different cloud microphysics and flow configurations in a relatively simple framework. Here, we conduct two-dimensional simulations of wave clouds with different horizontal wavelength (period $T$ between 100 and $1800 \mathrm{~s}$ ), cloud top temperature ( $t_{\mathrm{ct}}$ between -12 and $\left.-50^{\circ} \mathrm{C}\right)$, and cloud thickness $\left(z_{\mathrm{c}}=z_{\mathrm{ct}}-z_{\mathrm{cb}}\right.$ between 1000 and $4000 \mathrm{~m}$ ). This results in a total of 2268 simulations with different flow and/or thermodynamic conditions. All simulations are carried out with a vertical resolution of $50 \mathrm{~m}, 200$ vertical levels, and a time-step of $1 \mathrm{~s}$.

At each model level a vertical velocity time series is prescribed as follows:

$w(t, z)=A \cdot T^{-1} \sin \left(2 \pi t \cdot T^{-1}\right)$,

with $A=2880 \mathrm{~m}$. Multiple simulations are carried out with $T \in[100,1800] \mathrm{s}$. This formulation leads to a maximum vertical displacement of $\eta=A \pi^{-1} \approx 916.7 \mathrm{~m}$ irrespective of the chosen period $T$. This value of $\eta$ corresponds to the mean maximum vertical displacement of trajectories derived from the UM simulation, which pass through the wave cloud. The vertical velocity is set to zero after $T$. The time period $T$ controls the horizontal extent of the wave cloud. Using typical horizontal wind speeds of between 10 and $30 \mathrm{~m} \mathrm{~s}^{-1}$ the sampled $T$ range translates into along-flow cloud extend between 1 and $54 \mathrm{~km}$. This covers the range of wavelengths found in climatological studies of wave clouds (e.g. Grubisic and Billings, 2008). Although these climatological studies focus on lee wave clouds, and to our knowledge no climatology of cap clouds is available, this range should be representative of the isolated midlevel wave clouds that are the focus of the present study. Note that orographic clouds responsible for orographic precipitation typically have a much larger horizontal extent, at least if they do not form at isolated hills or mountains. Further note that the wavelengths cited above only pertain to the thermodynamic constraints for cloud formation. In the case of hydrometeors a finite evaporation timescale, the cloud can have a longer spatial extent (also in our KiD simulations).

The upstream temperature profile is given by a lapse rate of $-8.104 \times 10^{-3} \mathrm{~K} \mathrm{~m}^{-1}$ and a surface temperature of $32.1{ }^{\circ} \mathrm{C}$. The initial pressure profile is computed using the hydrostatic approximation with a pressure of $886.2 \mathrm{hPa}$ at $1000 \mathrm{~m}$ altitude (lowermost level). An initial profile of relative humidity is used with a relative humidity of $45 \%$ below the moist layer, $70 \%$ in the moist layer, and a linearly decreasing relative humidity above the moist layer with smooth transitions between the different layers: 


$$
\mathrm{RH}=\left\{\begin{array}{l}
0.45, \text { if } z<z_{\mathrm{cb}} \\
0.45+0.15 \cos \left(0.5 \cdot \frac{z_{\mathrm{cb}, t}-z}{z_{\mathrm{cb}, t}-z_{\mathrm{cb}}} \cdot \pi\right)^{2} \\
\quad \text { if } z_{\mathrm{cb}} \leq z<z_{\mathrm{cb}}+500 \mathrm{~m} \\
0.7, \quad \text { if } z_{\mathrm{cb}}+500 \mathrm{~m} \leq z<z_{\mathrm{ct}, t}-500 \mathrm{~m} \\
0.35+0.25 \cos \left(0.5 \cdot \frac{z_{\mathrm{ct}, t}-z}{z_{\mathrm{ct}}-z_{\mathrm{ct}, t}} \cdot \pi\right)^{2} \\
\quad \text { if } z_{\mathrm{ct}}-500 \mathrm{~m} \leq z<z_{\mathrm{ct}} \\
0.35-4 \times 10^{-5}\left(z-z_{\mathrm{ct}}\right), \text { if } z \geq z_{\mathrm{ct}} .
\end{array}\right.
$$

The initial profiles are based on the ICE-L case. However, we omit the vertical tilt of the orographic wave as well as the vertical gradient in maximum vertical velocity. Example cross sections from the KiD simulations are shown in Fig. 9.

Cloud microphysics are described by the CASIM module (Sect. 2.4) as in the UM simulations. As in the UM simulations, the sensitivity to the heterogeneous freezing parameterizations as well as assumptions for the $\mathrm{CCN}$ activation of INP is tested as detailed in Sect. 2.4. Together with the different settings for dynamic and thermodynamic conditions, we have a total of 45360 two-dimensional, idealized simulations.

\subsection{The CASIM module}

The Cloud-AeroSol Interacting Microphysics (CASIM) module is a recently developed double-moment cloud microphysics scheme for the UM (Shipway and Hill, 2012; Hill et al., 2015; Stevens et al., 2018; Miltenberger et al., 2018). Hydrometeors are represented by five different species, the size distribution of which is assumed to be a generalized gamma distribution with a fixed width. Hydrometeor mass and number of each hydrometeor species are computed prognostically. CASIM also includes prognostic mass and number of three soluble and one insoluble aerosol modes, for which log-normal distribution with a fixed width are assumed. Additional tracers for aerosols incorporated into hydrometeors are available, which are transported in accordance with the hydrometeors, i.e. including sedimentation. The in-cloud aerosol tracers allow for an explicit representation of immersion freezing and to investigate the vertical transport of aerosol by hydrometeor sedimentation.

Key microphysical processes to be investigated in the mixed-phase clouds are activation of aerosols to cloud droplets, heterogeneous freezing, growth (sublimation) of ice crystals by vapour deposition, aggregation of ice crystals, and sedimentation of ice-phase hydrometeors. All of these processes are represented in the CASIM module. Activation of aerosol to cloud droplets is described with the parameterization of Abdul-Razzak and Ghan (2000). For the activation of the "insoluble" aerosol category we assume a soluble fraction on the dust particles, which is prescribed as $0.01 \%$, $0.1 \%$, and $99 \%$ in three sets of sensitivity simulations. The chemical analysis of measured INP by Pratt et al. (2010) suggests that a substantial soluble fraction on INPs is realistic for the considered case. The activated INPs are then used to predict the ice crystal number concentration using parameterizations of immersion freezing from DeMott et al. (2010) (DM10), Niemand et al. (2012) (N12), Atkinson et al. (2013) (A13), Tobo et al. (2013) (T13), and DeMott et al. (2015) (DM15). For the A13 parameterization, we assume that $25 \%$ of the dust surface is feldspar. Deposition and contact freezing are currently not represented in CASIM, but previous studies suggest these are not of major importance for mixedphase orographic clouds. In addition, we have conducted simulations, in which the insoluble aerosol number concentration is directly used in these parameterizations irrespective of whether is was incorporated into liquid first. The latter is the standard approach in all models that do not track aerosol in hydrometeors. As the observed wave cloud reaches temperatures colder than $-38^{\circ} \mathrm{C}$ homogeneous freezing is also important. Homogeneous freezing of cloud droplets is parameterized in CASIM following Jeffery and Austin (1997). In order to test the impact of homogeneous freezing on the simulated cloud microphysical structure and in particular the ice crystal number concentration, an additional simulation has been conducted, in which homogeneous freezing is switched off ("nohom", heterogeneous freezing according to DM10). Thus in total, we have 21 sensitivity experiments with different representations of immersion freezing. For the sedimentation of ice-phase hydrometeors we use fixed diameter-fallspeed relations. For ice crystals the mass $m_{i}$ is related to the mean particle diameter $D_{i}$ via $m_{i}=$ $\frac{\pi}{6} \cdot 200 \mathrm{~kg} \mathrm{~m}^{-3} D_{i}^{3}$. The fallspeed $v_{i}$ is then computed according to $v_{i}=71.34 \mathrm{~m}^{0.3365} \mathrm{~s}^{-1} \cdot D_{i}^{0.6635}\left(\rho_{0} \rho^{-1}\right)^{0.5}$, where $\rho$ is the air density. The sedimentation fluxes will be sensitive to the parameters used in the mass-diameter and diameterfallspeed relations, but we leave exploring this sensitivity to a future study.

\subsection{Trajectory analysis}

Kinematic air mass trajectories are computed to detect changes in specific humidity and aerosol number density due to sedimenting hydrometeors in the wave cloud. Trajectories are calculated with the Lagrangian Analysis Tool (Sprenger and Wernli, 2015), which has been adapted to UM output, from the resolved wind field at $5 \mathrm{~min}$ temporal resolution. For the KiD model, trajectories are calculated analytically based on the prescribed wind field (Eq. 1).

\section{Comparison of modelled cloud properties to observational data}

On the 16 November 2007 a wave cloud forming in the lee of the Medicine Bow National Forest of Wyoming was observed with three subsequent aircraft passes through the 
(a)

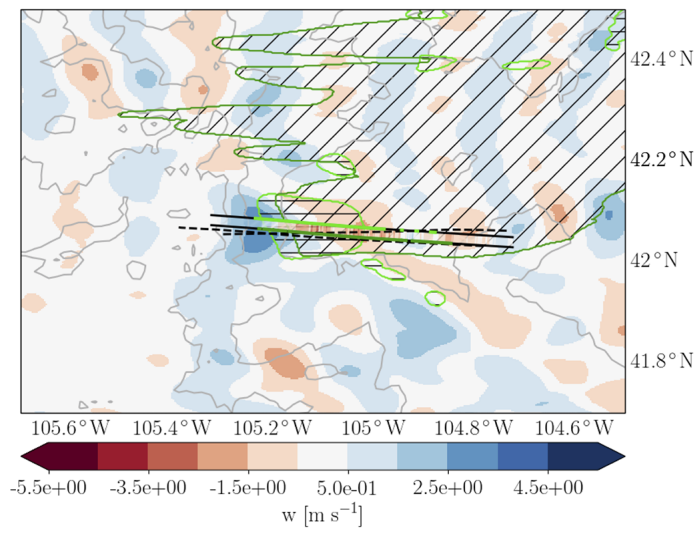

(b)

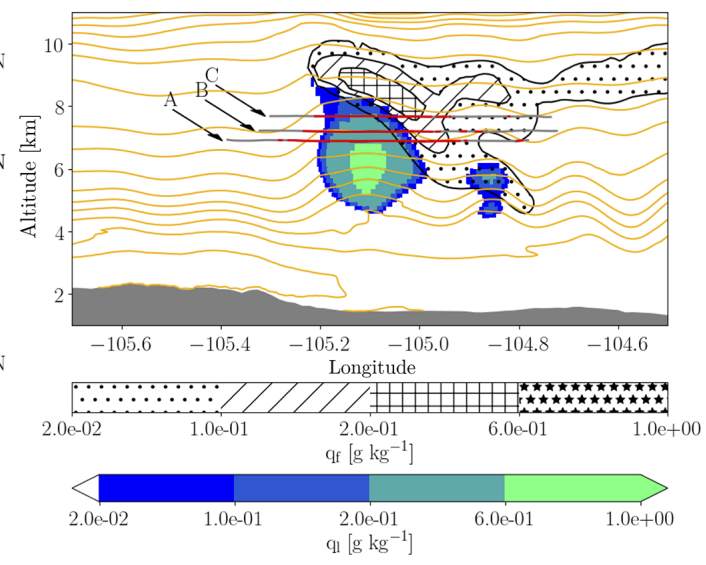

Figure 1. (a) The modelled vertical velocity field at $7200 \mathrm{~m}$, i.e. approximately the altitude of flight leg B, is shown by the colour shading (21:00 UTC). The dark blue (cyan) contour and horizontal (diagonal) hatching indicates where liquid (frozen) cloud water content in the model exceeds $0.02 \mathrm{~g} \mathrm{~kg}^{-1}$. The colour shading in the area between the two grey straight lines shows the observed vertical velocity along flight leg B, and the blue (green) colouring of the grey lines indicate observed cloud liquid (ice) exceeding $0.02 \mathrm{~g} \mathrm{~kg}^{-1}$. The black dashed lines show the location of the aircraft legs at 6900 and $6780 \mathrm{~m}$. Black contours indicate the topography. (b) Vertical cross section through the wave cloud at $42.05^{\circ} \mathrm{N}$ (21:00 UTC). The colour shading represents the modelled liquid water content; the contour lines with the hatching the modelled ice water content and the orange lines indicate isentropes. The horizontal lines show the projection of the flight path on the plane of the cross section, where red colouring of the lines indicates observed cloudy conditions (condensed water content larger than $10^{-7} \mathrm{~kg} \mathrm{~kg}^{-1}$ ). The grey area at the bottom of the plot shows the topography.

cloud at different altitudes. All flight legs are along or against the average wind direction. The average temperature of the three flight legs is $-25^{\circ} \mathrm{C}($ leg A; $z \approx 6.9 \mathrm{~km} ; \sim 20: 40 \mathrm{UTC})$, $-27.5^{\circ} \mathrm{C}($ leg $\mathrm{B} ; z \approx 7.2 \mathrm{~km} ; \sim 21: 00 \mathrm{UTC})$ and $-31^{\circ} \mathrm{C}$ (leg $\mathrm{C} ; z \approx 7.7 \mathrm{~km} ; \sim 21: 20 \mathrm{UTC}$ ). The cloud had an alongflow extension of about $40 \mathrm{~km}$ and a vertical extension of at least $1 \mathrm{~km}$. In the UM simulations a wave cloud of similar extent appears at the same location and roughly the same time ( $\pm 20 \mathrm{~min}$ ). A horizontal cross section of the modelled cloud at $\sim 7.2 \mathrm{~km}$, i.e. the mean altitude of flight leg $B$, is shown in Fig. 1a together with the flight tracks. The modelled vertical cloud structure at $42.05^{\circ} \mathrm{N}$ is shown in Fig. $1 \mathrm{~b}$ together with a projection of the aircraft legs on the plane of the cross section. These plots already indicate that modelled cloud location and extent agree well with the observed cloud. In the remainder of this section we compare the observed and modelled cloud microphysical structure in more detail.

\subsection{Thermodynamic conditions}

The geometry of wave clouds is strongly controlled by the upstream humidity and temperature profile as well as the vertical velocity field.

Figure 2a shows a comparison of the upstream temperature profile. The air temperature in the model is slightly higher than observed at all vertical levels, if evaluated at the time and location of the aircraft observations, with a deviation of about $2 \mathrm{~K}$ for flight leg A and less than $0.1 \mathrm{~K}$ for flight leg $\mathrm{C}$. The model suggests that the upstream temperature varied by up to $2.5 \mathrm{~K}$ during the time window of the observations, i.e. between 20:40 and 21:20 UTC.

The upstream specific humidity is compared in Fig. 2b. In general the model is somewhat more humid than observed at the time and location of flight leg $\mathrm{C}$ with a deviation of about $0.2 \mathrm{~g} \mathrm{~kg}^{-1}$. The model also suggests a quite large variability in the upstream specific humidity (roughly by a factor of 2) in the time window of the observations with a gradual moistening before 21:00 UTC and a subsequent drying. As all observation data are within the modelled spread of specific humidity values, the agreement is fairly good. As the temporal evolution or zonal variation in the humidity profile is not well characterized by the observations, it is not straightforward to assess if and to what degree the differences between model and observed specific profiles impact the condensate content along the flight paths.

In Fig. 3 the observed vertical velocity along the three flight legs is compared to the modelled vertical velocity. While in the figure we also show the vertical velocity interpolated onto the flight path (dark blue), for the analysis we use hypothetical flight paths, which are parallel to the mean modelled streamline (grey lines). Hypothetical flight paths have a horizontal spacing of $250 \mathrm{~m}$ in zonal direction and run through the centre of the wave clouds, i.e. have a peak vertical velocity larger than $2.5 \mathrm{~m} \mathrm{~s}^{-1}$. Using these hypothetical flight paths instead of the actual aircraft track eliminates the impact of slightly different horizontal wind direction in model simulations and the observed flow. The mean flow is from west to east, i.e. from left to right in these plots, and 
(a)

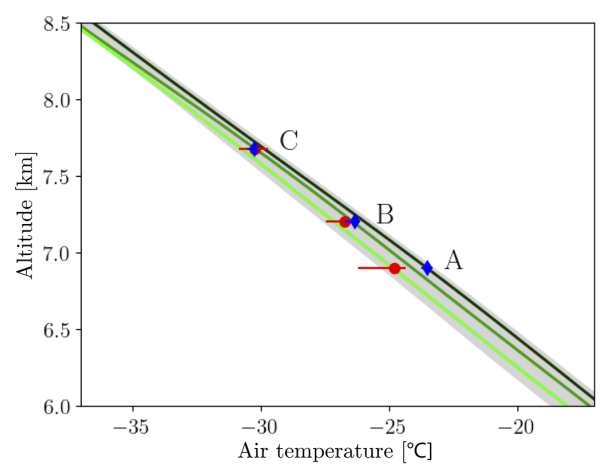

(b)

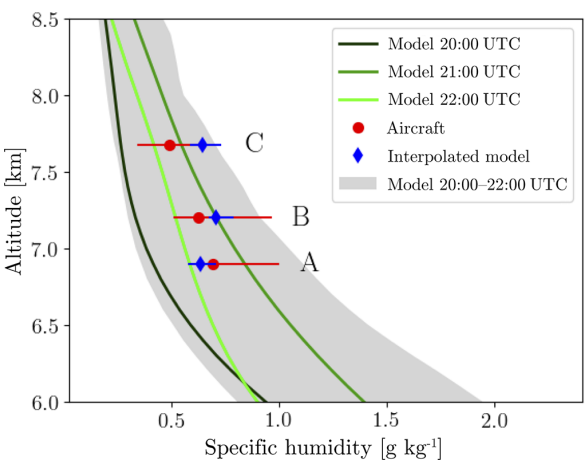

Figure 2. Comparison of (a) upstream temperature and (b) specific humidity profiles from the UM simulation and aircraft data. Upstream conditions from aircraft data are computed from the non-cloudy sections of the aircraft legs west of $-105^{\circ}$ E. Red circles indicate the mean value along these portions of the aircraft legs, and the bars indicate the variability. The model values are taken from the grid column closest to the average location of these upstream aircraft segments (green lines) at times between 20:00 and 21:00 UTC, i.e. bracketing the time of the observations between $\sim 20: 40$ and $\sim 21: 20$ UTC. The cyan shading shows the variability in temperature and specific humidity in this grid column for all output times between 20:00 and 22:00 UTC. The blue diamonds and bars show the model data interpolated to the flight track and evaluated in the same way as the aircraft data.

the cloud forms at the first peak in vertical velocity. The amplitude of the wave in terms of the vertical velocity is well captured in the model at all three altitudes with maximum deviations of less than $1 \mathrm{~m} \mathrm{~s}^{-1}$. Note that the uncertainty in the vertical velocity observations can be up to several tenths of $1 \mathrm{~m} \mathrm{~s}^{-1}$ (e.g. Field et al., 2012). The width of the positive vertical velocity peak is slightly larger in the model than in the observations, and the peak occurs slightly further east. The secondary peaks in vertical velocity downstream of the main wave are less well captured, particularly for flight leg C (Fig. 3a). For the cloud formation, the vertical displacement of air parcels is more important than the maximum vertical velocity. The vertical displacement depends on the amplitude, wavelength, and vertical structure of the wave. As vertical velocity observations are only available along the flight track, it is not possible to rigorously evaluate the modelled vertical displacement.

In summary, the modelled air temperature deviates less than $1 \mathrm{~K}$ from observations, the specific humidity less than $0.2 \mathrm{~g} \mathrm{~kg}^{-1}$, and the vertical velocity less than $1 \mathrm{~m} \mathrm{~s}^{-1}$. To our knowledge this is the first study, in which a direct comparison of aircraft measurements and simulations from a regional numerical weather prediction is done. There are many sources of uncertainty in regional numerical weather prediction models including uncertainty in the analysis used for initial and boundary conditions, the representation of orography, drag, dynamics, and microphysics. In addition, upstream conditions vary in time, which is not fully captured by the aircraft measurements. Given these issues, the agreement between modelled thermodynamic and dynamic conditions seems to be sufficiently good for an in-depth comparison of the cloud microphysical structure as well as investigations of the vertical fluxes of water vapour and aerosol. Due to the small temperature bias in the model, in the following we always compare the aircraft data with the model data $200 \mathrm{~m}$ above the altitude of the flight track. This eliminates the temperature bias (Fig. S1 in the Supplement) and allows for a better comparison of the ice nucleation.

\subsection{Cloud structure}

The microphysical data along the various aircraft legs allow for a detailed analysis of the microphysical processes due to the mainly laminar flow in the wave clouds, albeit not providing a truly Lagrangian perspective. Note that all flight legs are along or against the average wind direction, i.e. streamlines are crossed at least twice (see also Field et al., 2012). The in-cloud, updraught-dominated region of the flight legs is characterized by a relatively constant air temperature (variations $<0.5 \mathrm{~K}$ ) and specific humidity (variations $<0.1 \mathrm{~g} \mathrm{~kg}^{-1}$ ) (Figs. $4 \mathrm{a}-\mathrm{c}, \mathrm{S} 1$ ) in both the model and the observational data. The constant specific humidity reflects water saturated conditions given the observed constant in-cloud temperature. Consistent with the similar temperature in model and observation, the in-cloud specific humidity is very similar in both datasets. This is partly by design as the measured specific humidity was corrected such that the relative humidity is on average $100 \%$ in regions with liquid water content larger than $0.02 \mathrm{~g} \mathrm{~kg}^{-1}$ (Heymsfield et al., 2011).

The deviations in the spatial distribution and amount of total condensate content between model and observations are larger than in all other variables considered so far (Fig. $4 d-$ f). In the upstream, updraught-dominated cloud section, i.e. west of $\sim-105.1^{\circ} \mathrm{E}$, the total condensate amount is clearly larger than in the observations for flight legs $\mathrm{A}$ and $\mathrm{C}$. For these flight legs total condensate data from the various avail- 
(a) Flight leg $\mathrm{C}$

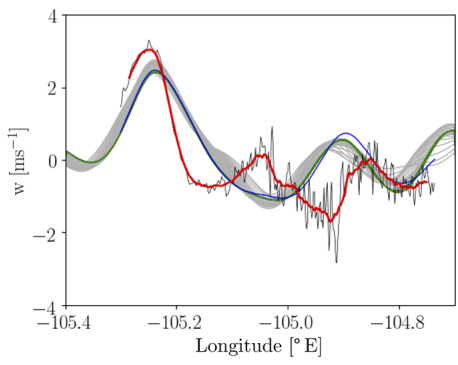

(b) Flight leg B

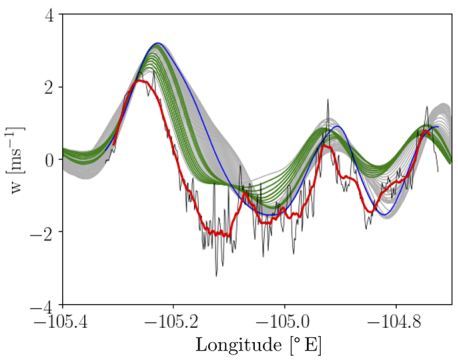

(c) Flight leg A

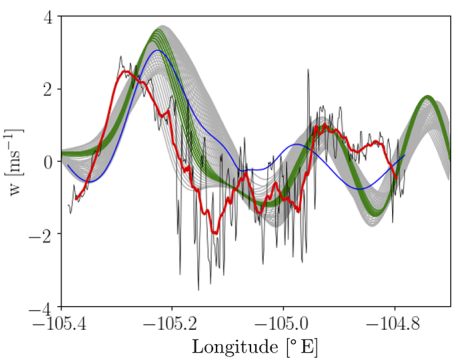

Figure 3. Vertical velocity along (a) flight leg C (7680 m, 21:20 UTC), (b) flight leg B (7200 m, 21:00 UTC), and (c) flight leg A (6900 m, 20:40 UTC). The red solid line shows the aircraft data smoothed with a $20 \mathrm{~s}$ moving average filter (full $1 \mathrm{~Hz}$ data shown by the thin black line). The blue line shows the modelled aircraft velocity interpolated to the aircraft track. The grey lines show the vertical velocity along tangents to the mean streamline (including a deviation corresponding to the deviation between the observed mean horizontal wind direction and the direction of the aircraft track), for which the peak vertical velocity exceeds $2.5 \mathrm{~m} \mathrm{~s}^{-1}$. This threshold was chosen to focus on the centre of the wave cloud only. The green line shows the tangent for which the Pearson correlation (including a lag of $\pm 20 \mathrm{~s}$ ) with the observed vertical velocity is larger than 0.95 . To account for the temperature bias of the model, model data are taken $200 \mathrm{~m}$ above the altitude of the flight track.

(a) Flight leg C

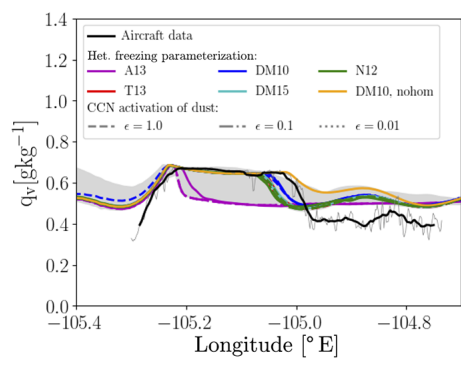

(d) Flight leg C

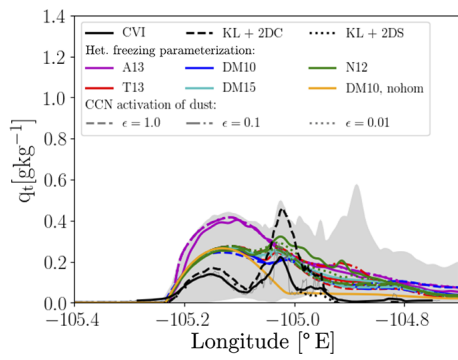

(b) Flight leg B

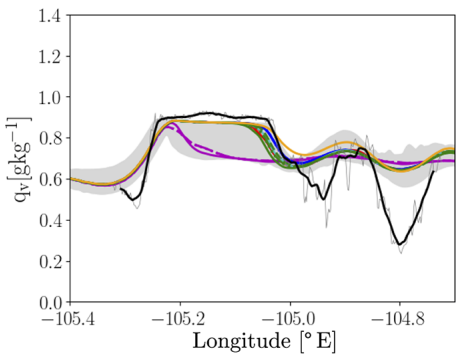

(e) Flight leg B

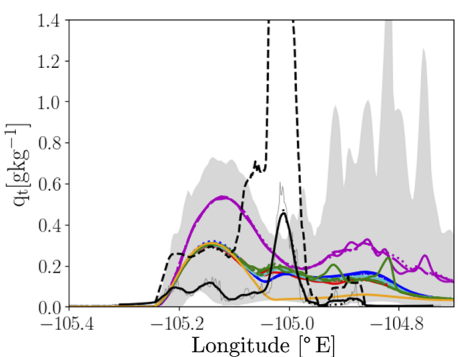

(c) Flight leg A

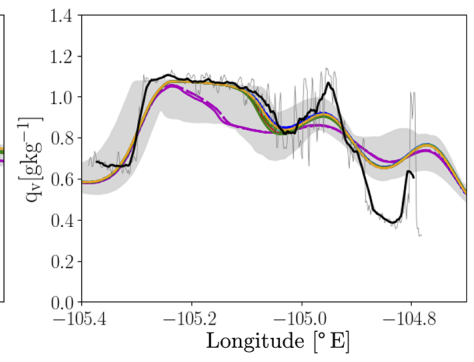

(f) Flight leg A

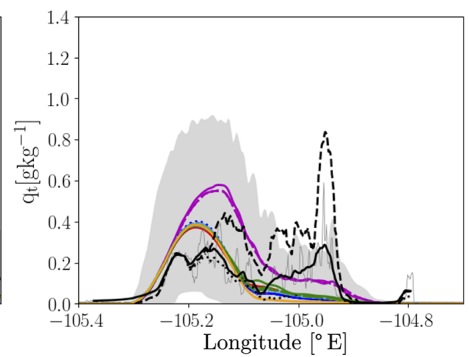

Figure 4. Comparison of (a-c) specific humidity and (d-f) total condensation mass mixing ratio for the three different flight legs. The flight legs are shown in the sequence of decreasing flight altitude from left to right. The thick black line shows the smoothed aircraft data (thin black line shows $1 \mathrm{~Hz}$ data). For the total water content (d-f) data from the CVI (thick solid black line) as well as the sum of King liquid water probe data and 2DS (2DC) data (black dashed (dotted) line) are shown. Model data are interpolated to the same tangents of the mean streamlines as used in Fig. 3. With the exception of the CVI data, the observed total water content includes only ice crystals larger than $50 \mu \mathrm{m}$. From the model results, the ice water content for ice crystals larger than $50 \mu \mathrm{m}$ is computed by integrating over the respective part of the assumed size distribution in the model using the prognostic variables of ice number concentration, ice mass mixing ratio, and the fixed shape parameter. The modelled variability in the variable along all these hypothetical flight paths is shown by the grey shading, while the thick coloured lines show the median values for simulations. The different coloured lines represent the different ice nucleation schemes, and different line styles indicate different assumptions about the amount of soluble material in the dust particles (solid: all dust acting as INP). 
able sensors agree well in this part of the cloud (deviations of maximum value less than $3 \%$ and $20 \%$, respectively). For flight leg B, King liquid water probe measured about twice the amount of condensate as the CVI. The King liquid water probe data agree with the model data within $60 \%(10 \%$, $100 \%)$ for flight legs $\mathrm{A}(\mathrm{B}, \mathrm{C})$ for the peak value. In most model runs as well as in the observational data there is little ice in this part of the cloud (Fig. 5), and hence the total condensate is controlled by the upstream humidity and the total lifting up to the considered point. Given the small deviations in upstream humidity between model and observations, the higher modelled total condensate values are likely due to the somewhat larger vertical velocities, which together with the similar horizontal wavelength result in larger vertical displacements of air parcels than in the observations (Fig. 3). Simulations using the A13 parameterization have an even higher total condensate amount. In these simulations glaciation occurs very early (Fig. 5), and hence the saturation pressure over ice is relevant for the equilibrium condensate amount and not the saturation pressure over water. In the cloudy region further downstream, i.e. downstream of $\sim-105.1^{\circ} \mathrm{E}$, observations indicate a large increase in condensate amount, despite the prevailing downdraft. Note observational data from various sensors diverge in this part of the cloud. In the model, there is a small increase in total condensate downstream of $\sim-105.1^{\circ} \mathrm{E}$ most conspicuous for flight leg C (Fig. 4f). This increase is, however, smaller than in the observations, in particular for flight legs B and A. In the simulation without homogeneous freezing, the increase is absent, suggesting that the increase in condensate is due to homogeneously formed ice crystal being transported in the downdraft. It is likely that the increase observed is due to the same mechanism.

The the horizontal extent of the cloud, in which liquid hydrometeors are present, is similar in the observations and the model simulation, further supporting the above conclusion of a good representation of the thermodynamic structure of the wave cloud in the model simulations (Fig. S2). As discussed for the total condensate, the liquid water content is overestimated by the model most likely due to differences in the vertical displacement or upstream humidity of the air parcels. The cloud droplet number concentration deviates by less than $20 \mathrm{~cm}^{-3}$ between model and observations for all simulations except those using A13, for which cloud droplets are depleted due to very efficient heterogeneous freezing (Fig. S2).

The comparison of frozen hydrometeor mass mixing ratios shows that the modelled onset of significant cloud glaciation is roughly consistent with the observations along the flight legs $\mathrm{B}$ and $\mathrm{C}$ at $\sim-105.1^{\circ} \mathrm{E}$ but occurs later on the flight leg A (model: $\sim-105.13^{\circ} \mathrm{E}$; observations: $\sim-105.18^{\circ} \mathrm{E}$; Fig. 5a-c). The steep increase in the mass mixing ratio on flight legs $\mathrm{B}$ and $\mathrm{C}$ (downstream of $\sim-105.1^{\circ} \mathrm{E}$ ) is associated with a rapid increase in ice number concentration in the model (Fig. 5d, e) and occurs in the downdraft region. While both the 2D-C and the 2D-S data agree quite well in terms of the ice crystal number concentrations (within factor 2), the estimated ice crystal mass diverges. The large increase in ice crystal mass and number in the downdraft region is likely due to the downward transport of ice crystals formed by homogeneous freezing by the descending air with a minor contribution of sedimentation. The importance of homogeneously formed ice in the downdraft region is supported by the divergence of ice crystal number concentrations in the simulations with and without homogeneous freezing (compare orange and blue line in Fig. 5d-f). In the observations ice mass and number concentration increase also in the downdraft region. However, the ice water content, at least in the 2D-C data, increases before the strong increase in ice crystal number concentration. In the model the steep increase in crystal number concentrations occurs earlier than in the observations. We hypothesis that the earlier increase in ice water content, which generally coincides with the start of the downdraft regions is due to larger displacements of air parcels in the model (somewhat larger vertical velocities, Fig. 3) and hence a stronger downward transport of homogeneously formed ice crystals. Alternatively, too early an onset of homogeneous freezing or too rapid a sedimentation of ice crystals could also lead to the observed differences between model and observation. Based on the available data, none of these options can be ruled out. The first ice crystals larger than $50 \mu \mathrm{m}$ appear in approximately the same location as in the observations at all altitudes, however with much larger concentrations. This suggests too large a droplet mass in the freezing event consistent with the overestimation of liquid condensate. Maximum ice crystal concentrations for most simulations agree within a factor of 2 on flight legs $\mathrm{A}$ and $\mathrm{B}$, while they are about a factor 10 larger on the flight leg C (Fig. 5d-f). However, if not only the maximum concentration is considered, modelled and observed ice crystal number concentration is within a factor of 2 only for the lowest flight level, with differences of almost an order of magnitude on the higher flight levels. As pointed out earlier, simulations using the A13 parameterization strongly overestimate the ice crystal number concentration inducing too early an onset of glaciation. Different assumptions about the $\mathrm{CCN}$ activation of dust particles (different line styles of the same colour in Fig. 5) have only a small impact on the modelled ice crystal mass and number concentrations, with the largest impact in simulations using the N12 parameterization and flight leg C. Even for simulations with $\mathrm{N} 12$ the resulting differences are much smaller than the difference to the observed time series, and it is not clear whether representing $\mathrm{CCN}$ activation of dust particles yields an improvement based on these. As expected the location, at which ice crystals first appear, is shifting slightly downstream in simulations with a smaller soluble fraction on the dust particles. The horizontal extent of the ice tail in the model is overestimated for all flight legs, except flight leg A (Fig. 5c, f). The longevity of ice crystal in the model is very likely related to the smaller average ice crystal mass, i.e. the ratio of ice crystal mass mixing ratio and number concentra- 
(a) Flight leg $\mathrm{C}$

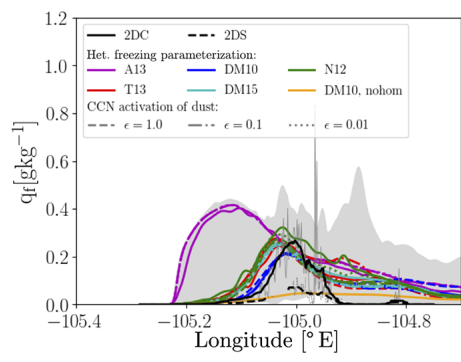

(b) Flight leg B

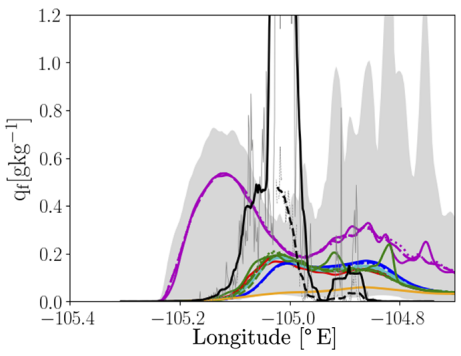

(c) Flight leg A

(f) Flight leg A

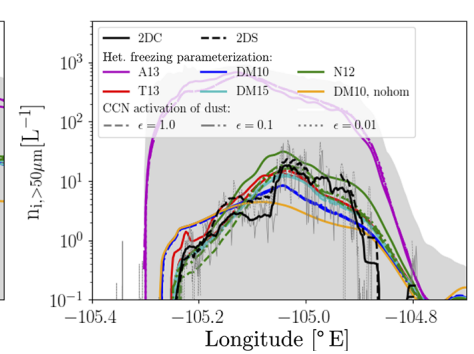

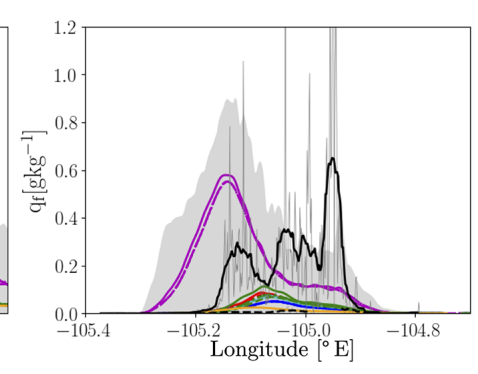

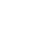

(d) Flight leg $\mathrm{C}$

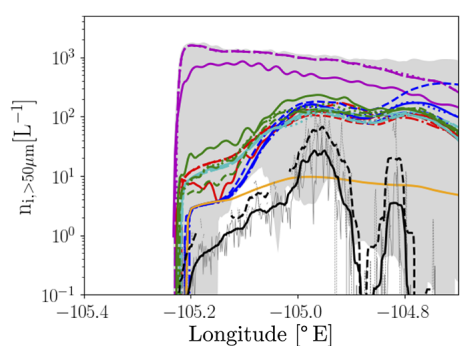

(e) Flight leg B

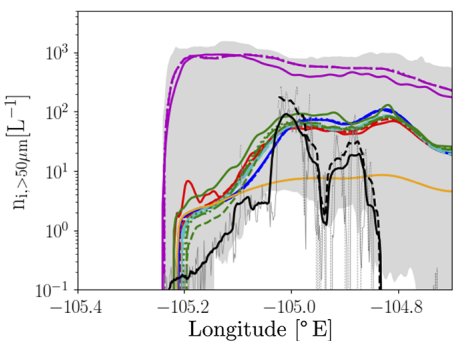


tal number concentrations. In order to test this hypothesis in the model we focus on the ice crystal number concentration in the updraught region of the cloud, i.e. west of $-105.1^{\circ} \mathrm{E}$, which is not influenced by homogeneously nucleated ice crystals (compare orange and blue lines in Fig. 5d-f). This modelled ice crystal number concentration is compared with the ice crystal number concentration expected from the heterogeneous freezing parameterization based on the temperature and the upstream dust profile (compare coloured markers and lines in Fig. 6). In general these agree very well, suggesting that we can use observations of ice crystal number concentration from the updraught region of orographic wave clouds to constrain the temperature dependence of INP concentration. The observed ice crystal number concentrations from the 2D-C for the different flight legs are shown in the black boxplots in Fig. 6. These data suggest a very weak temperature dependency of heterogeneous freezing in the observed wave cloud, which is only consistent with the DM10 parameterization. All other parameterizations appear to have too strong a temperature dependence. However, the temporal evolution of the upstream dust concentrations has to be considered as this can result in shallower or steeper temperature apparent temperature dependence. As the upstream dust profile was not monitored continuously and is constructed from the upstream observations along the flight legs, only the potential impact of time-varying dust concentrations can be assessed. For this we use the minimum and maximum observed upstream dust concentrations, irrespective of the observed altitude, to derive the resulting impact on the expected ice crystal number concentration; the shaded area in Fig. 6 indicates the spread in expected number concentrations, while the dashed lines represent a scenario with continuously decreasing upstream dust concentrations. If the latter scenario is considered, the observations are consistent also with the T13 simulation. Reliable observational data of the ice crystal size distribution are only available for particles larger than $50 \mu \mathrm{m}$. Hence, the analysis here considers only the largest observed ice crystal number concentration in the updraught region. While this limits the impact of different mean droplet volumes during freezing and potential differences in depositional growth, it introduces additional uncertainty into the comparison.

The comparison shows that all heterogeneous freezing parameterization, except that from Atkinson et al. (2013) are compatible with the observations within the anticipated uncertainty range. For simulations with the A13 parameterization we assume feldspar to be constitute $25 \%$ of the dust surface, which is at the upper end of the composition of natural dust Atkinson et al. (2013). If a value closer to the lower bound of $1 \%$ would have been used, A13 would be closer to the other parameterizations at $-25^{\circ} \mathrm{C}$ but still predicts too high ice crystal concentrations at colder temperatures (Fig. S3). The experiment closest to the observations is DeMott et al. (2010), followed by DeMott et al. (2015) and Tobo et al. (2013) (compared black boxplots with dashed lines and

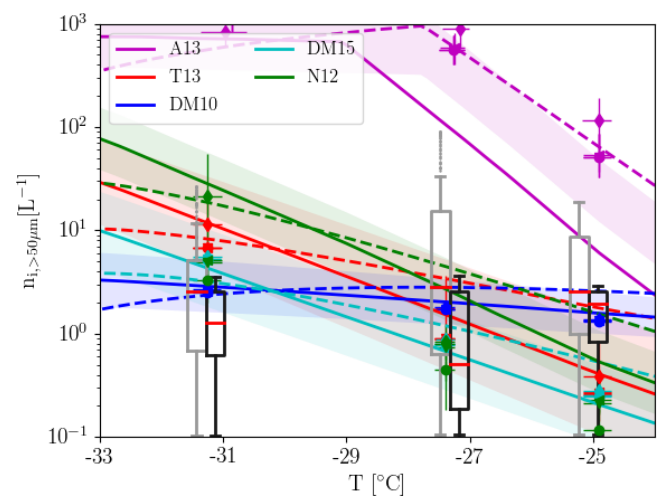

Figure 6. Temperature dependency of ice crystal number concentration against air temperature from observations (2DC, boxplots) and UM model simulations (symbols; colours represent simulations with different ice nucleation schemes according to legend in Fig. 4a). Model data are interpolated to the hypothetical flight tracks and only considered in the first part of each flight leg, i.e. the updraught region. Observational data are also subsampled to include only data from the updraught region, which are shown in the black boxplots (grey boxplots show all data). The solid lines show the expected ice crystal number concentration based on ice nucleation only using the prescribed dust profiles. The colour shading illustrates the expected ice crystal number concentration for dust number concentrations within a factor of 2 of the used profile, i.e. compatible with range observed upstream of the cloud. Assuming a linear decrease in the upstream dust concentration over the time period of the observations together with the assenting flight pattern results in expected ice crystal number concentration as shown by the dashed lines.

shading in Fig. 6). However, it is unclear whether these parameterizations are most applicable in other cases or other geographic regions, as the INP activity is known to strongly depend on the chemical composition and size distribution of aerosols (e.g. Petters and Wright, 2015). Nevertheless, the presented results suggest that wave clouds can be used as natural laboratories to investigate the temperature dependence of heterogeneous freezing. To formulate constraints on the parameterizations, observations from more wave cloud events are necessary. In any future campaigns targeting orographic wave clouds, an emphasis should be placed on characterizing the full ice crystal size distribution as well as the temporal (and spatial) variation in the upstream aerosol concentration.

\section{Modification of water vapour and aerosol profiles}

\subsection{ICE-L case}

One important impact of wave clouds on the evolution of the larger-scale atmospheric state is modification of water vapour and aerosol profiles through sedimentation of hydrometeors (in addition to the alteration of radiative fluxes). 
Vertical transport of water vapour and aerosols occurs in all clouds, but it is likely easier to observe these fluxes in wave clouds. The downward transport of water vapour depends strongly on the size and fall velocity of the formed hydrometeors. Thick warm-phase orographic clouds are known to produce significant precipitation. The downward water vapour transport is much smaller for mixed-phase wave clouds due to the smaller size and fallspeeds of ice crystals. However, according to the model simulations, the largest ice crystal diameters are on the order of 400-600 $\mu \mathrm{m}$ (not shown), which results in vertical displacement of about $700 \mathrm{~m}$ due to sedimentation over the roughly $30 \mathrm{~min}$ air parcels spend inside the cloud. Here, we quantify the downward transport of water and aerosol by considering the change in total water or aerosol number concentrations along trajectories through the wave cloud, $\Delta q_{\mathrm{t}}\left(z_{0}\right)$. We refer to the vertically integrated increase in total water in the lower part of the profile (equal to the decrease in total water in the upper part of the profile) as the total downward moisture transport $\left(\Delta q_{\mathrm{t}}\right)$. Fig. 7a and $\mathrm{b}$ show the Lagrangian change in total water along backwards trajectories starting in the lee of the cloud for simulations with the A13 and DM10 heterogeneous freezing parameterizations. In the time period after 80 min a typical sedimentation signal is obtained, with a depletion of the total water content in parcels above about $7 \mathrm{~km}$ and an increase in parcels below. At earlier times, this pattern is repeated twice in the vertical, and a closer inspection reveals that there are two cloudy layers in the UM simulations, one formed by homogeneous nucleation and the lower one by heterogeneous freezing. To assess the differences between simulations with different heterogeneous freezing, average profiles for the two time periods from all simulations are shown in Fig. 7c and d. The shading indicates the variability resulting from different starting latitudes of the trajectories. The mean profiles for simulations with all parameterizations except A13 are very similar and much smaller than the temporal variability. The larger INP concentrations predicted by A13 lead to much larger change in total water content $\Delta q_{\mathrm{t}}\left(z_{0}\right)$ particularly in the first part of the considered time period. The assumptions about the $\mathrm{CCN}$ activation of dust lead to very small differences in $\Delta q_{\mathrm{t}}\left(z_{0}\right)$ (Fig. S4a, b).

The CASIM microphysics explicitly considers the vertical transport of dust particles by hydrometeor sedimentation and therefore allows us to quantify the downward transport of aerosol by the wave cloud. The Lagrangian change in aerosol content is shown in Fig. 8. The vertical structure is different to $\Delta q_{\mathrm{t}}\left(z_{0}\right)$, with aerosol depletion only occurring at the very top of the cloud (above $\sim 9.7 \mathrm{~km}$ ) and increases in aerosol number concentrations mainly towards cloud base. The modifications of the dust profiles are more sensitive to changes in the heterogeneous freezing parameterization than those of the total water content, with larger changes also in the shape of the profiles. However, the differences are again smaller than the temporal variability. The treatment of the $\mathrm{CCN}$ ac- tivation of dust (using all dust for heterogeneous freezing or presenting activation assuming some soluble fraction on dust particles) has a much larger impact on the vertical aerosol transport than on the moisture transport. The resulting differences in the profile are on the same order of magnitude as the temporal variability (Fig. S4c, d).

It would be interesting to constrain the downward transport with observational data, in particular given the uncertainties surrounding diameter-fallspeed relations often used in bulk models. The maximum change in $q_{\mathrm{t}}$ of about $0.1 \mathrm{~g} \mathrm{~kg}^{-1}$ is, however, smaller than the temporal variation in the specific humidity (Fig. 2) during the average time a parcel needs to transit through the wave cloud (i.e. $\sim 30 \mathrm{~min}$ ). As the aircraft data do not provide information on the temporal evolution of upstream humidity, it is not possible to use the aircraft data to constrain the vertical moisture transport by sedimentation. In addition, for such an assessment the construction of air parcel trajectories from the observed velocity field would be required. While this is in principle possible (e.g. Field et al., 2012), for the assessment of downward moisture transport, the error in the upstream positions of air parcels would need to be smaller than $500 \mathrm{~m}$ owing to the vertical gradient of upstream specific humidity. This is not feasible given the sparse observations of velocity (only sampled along flight legs) and the uncertainty in measured vertical velocity. However, detailed observations of the 3D velocity field for example with an on-board lidar system and a better characterization of the upstream and downstream humidity profiles, e.g. sampling in a quasi-Lagrangian manner, there is a potential for future field campaigns to constrain vertical transport of moisture by sedimenting hydrometeors from wave clouds.

Because wave clouds offer such an opportunity to detect sedimentation mediated vertical transport of moisture and aerosol we assess in the following section how its amplitude depends on the upstream thermodynamic conditions, which determine the cloud thickness and cloud top temperature, and on the horizontal wavelength of the gravity wave, which controls the horizontal extent of the cloud.

\subsection{Downward moisture transport by sedimentation in idealized simulations}

The modification of moisture and aerosol profiles by hydrometeor sedimentation is investigated for the ICE-L case study in the previous section. However, the cloud-integrated sedimentation fluxes will vary for different wavelength, cloud top temperatures, and cloud thicknesses and so will their impact on the vertical profiles of aerosol and moisture. To assess these dependencies, we use two-dimensional, idealized simulations with the KiD model (Sect. 2.3). Using an idealized model for this assessment allows us to vary the wavelength of the gravity wave, which would require changing the topography in the Unified Model. In addition, we can carry out a large number of simulations sampling a large 
(a)

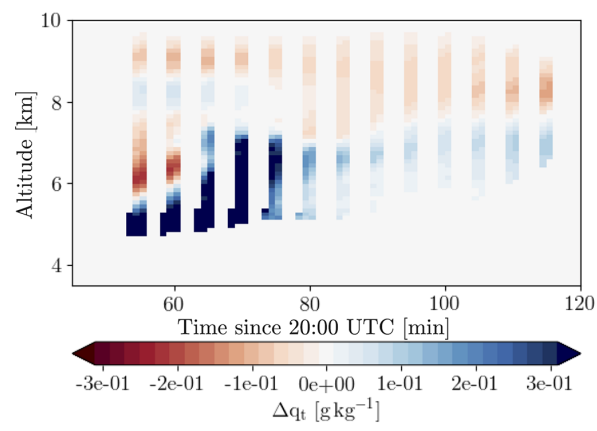

(c)

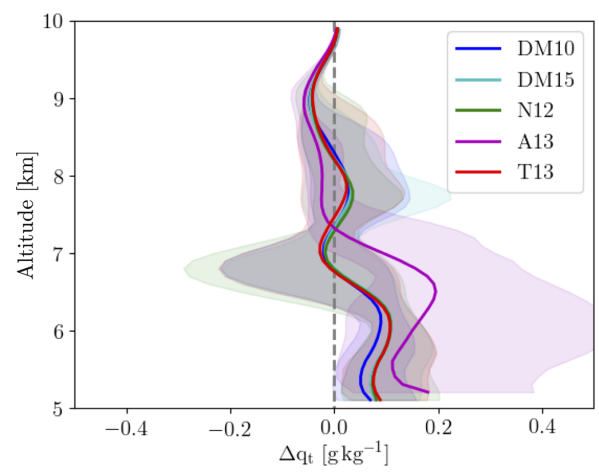

(b)

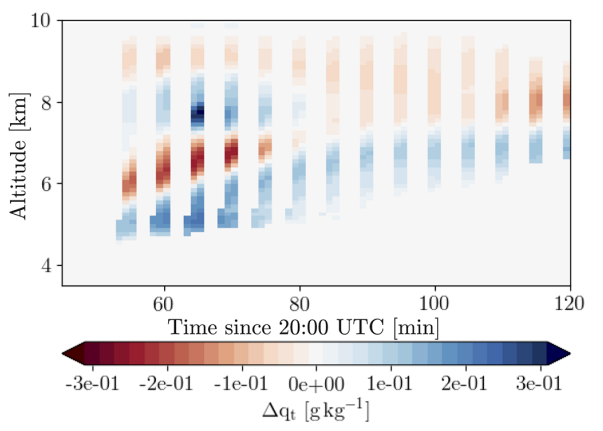

(d)

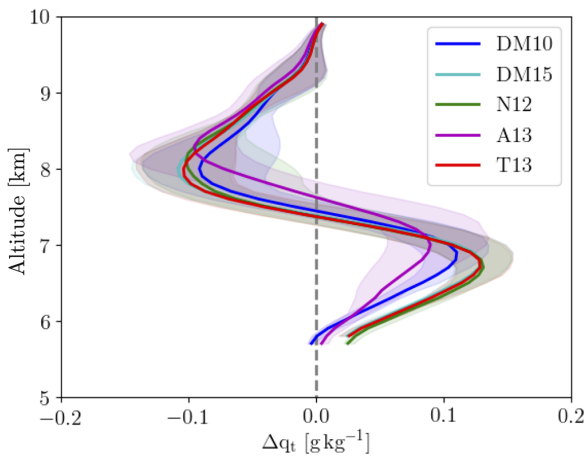

Figure 7. (a, b) Difference in total water mass mixing ratio $\Delta q_{\mathrm{t}}$ between $-105.35^{\circ} \mathrm{E}$ (upstream) and $-104.78^{\circ} \mathrm{E}$ (downstream) along backward trajectories for simulations using the (a) A13 and the (b) DM10 ice nucleation parameterization. The differences are calculated as downstream values minus upstream values. The plot shows values at $42.1^{\circ} \mathrm{N}$, i.e. downstream of the centre of the wave cloud. The times on the abscissa indicate the arrival time of the trajectories at the downstream location. (c, d) Mean profiles of $\Delta q_{\mathrm{t}}$ for all simulations averaged between (c) 21:10 and 21:30 and (d) 21:40 and 22:00 UTC. The different colours correspond to simulations with different ice nucleation parameterizations, while the shading represents the temporal variability in the profiles. Note the travel time of the trajectories between the upstream and the downstream location is about 30 and $40 \mathrm{~min}$.

proportion of the relevant phase space, which would not be possible with the UM due to the much larger computational costs. But we are able to link back to the case study by including the observed case in the phase space explored. Two exemplary realizations of wave cloud in the KiD model are shown in Fig. 9 along with the profiles of Lagrangian changes in moisture $\left(\Delta_{\mathrm{Lagr}} q_{\mathrm{t}}\right)$ and aerosol $\Delta_{\mathrm{Lagr}} m_{\mathrm{du}}$. As in the UM simulations, the profiles of moisture and aerosol changes have distinctly different shapes: while aerosol changes are concentrated at cloud top and cloud base, moisture changes occurring throughout the cloud with peak values in the upper and lower half of the cloud, respectively.

To explore the variation in the downward transport as a function of cloud geometry, we focus on the cloud-scale downward moisture (aerosol) transport $\Delta q_{\mathrm{t}}\left(\Delta m_{\mathrm{du}}\right)$, which we define as the integral of positive $\Delta_{\text {Lagr }} q_{\mathrm{t}}\left(\Delta_{\mathrm{Lagr}} m_{\mathrm{du}}\right)$. Note that the integral over negative $\Delta_{\text {Lagr }} q_{\mathrm{t}}\left(\Delta_{\text {Lagr }} m_{\mathrm{du}}\right)$ gives the same results due to mass conservation, albeit of course with a different sign (not shown). For further analysis we split the sedimentation flux into sedimentation of liquid $\left(\Delta_{\text {Lagr }} q_{\mathrm{t}, 1}\right)$ and frozen hydrometeors $\left(\Delta_{\mathrm{Lagr}} q_{\mathrm{t}, 1}\right)$, which display a differ- ent dependence on the explored phase-space control parameters. Figure 10a summaries $\Delta q_{\mathrm{t}, \mathrm{f}}$ for all investigated wave periods (abscissa) and cloud top temperatures (ordinate) for a cloud depth of $2000 \mathrm{~m}$. Figure S5a is the equivalent for $\Delta_{\text {Lagr }} q_{\mathrm{t}, 1} . \Delta_{\text {Lagr }} q_{\mathrm{t}, 1}$ is only important for cloud top temperatures warmer than $\sim-30^{\circ} \mathrm{C}$ (Fig. S5b). In both the UM and the KiD model rain formation is included as is the sedimentation of cloud droplets and rain drops. Rain formation is found in all simulations to be negligible, with the rain mass mixing ratio at least 1 order of magnitude smaller than the mass mixing ratio of any other hydrometeor. This is due to the short in-cloud residence timescales $(<30 \mathrm{~min})$, which according to the timescale analysis in Stevens and Seifert (2008) and Miltenberger et al. (2015) is too short for significant rain formation. As the dependence of $\Delta_{\mathrm{Lagr}} q_{\mathrm{t}, 1}$ is quite different from $\Delta_{\text {Lagr }} q_{\mathrm{t}, \mathrm{f}}$, and considerations of $\Delta_{\text {Lagr }} q_{\mathrm{t}, 1}$ are already published in Miltenberger et al. (2015), the following analysis will predominantly focus on $\Delta_{\text {Lagr }} q_{\mathrm{t}, \mathrm{f}} . \Delta_{\text {Lagr }} q_{\mathrm{t}, \mathrm{f}}$ has also been computed from the UM simulations and is shown by the colour-filled circle at $T=1800 \mathrm{~s}$ and $t_{\mathrm{ct}}=-45^{\circ} \mathrm{C}$, which corresponds to the average cloud top temperature and resi- 
(a)

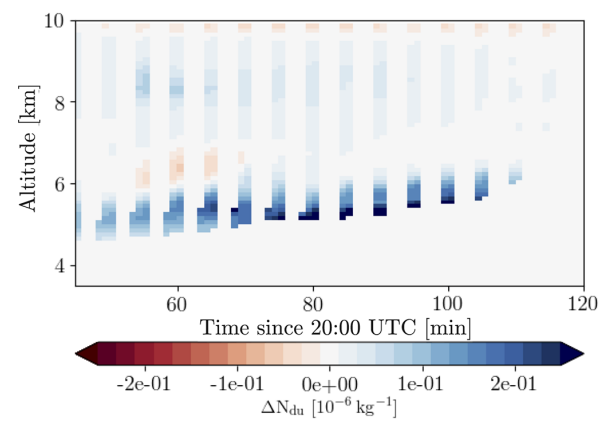

(c)

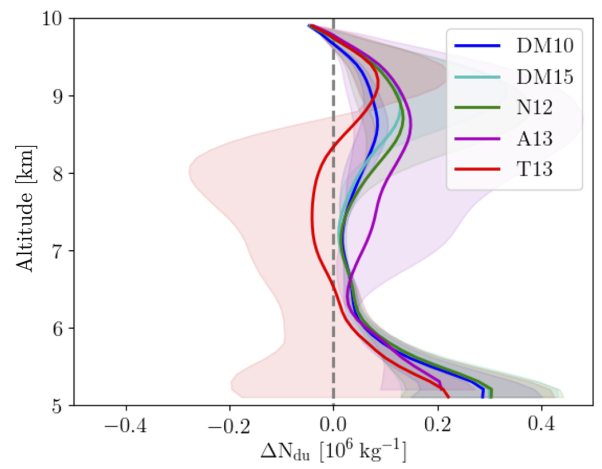

(b)

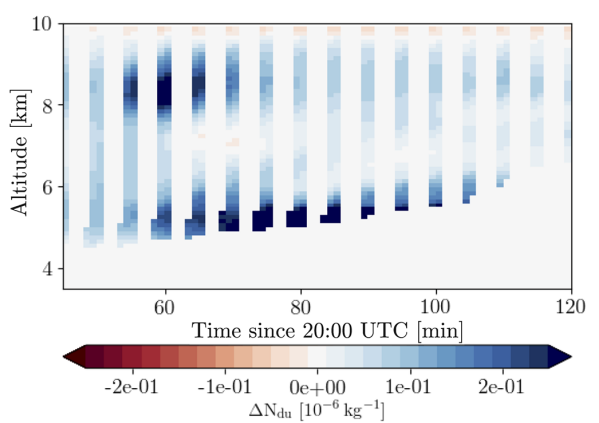

(d)

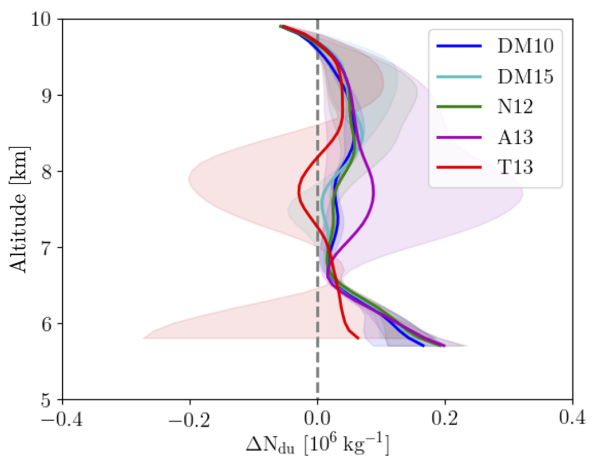

Figure 8. As Fig. 7 but showing the change in dust number concentration.

dence time of parcels in the orographic cloud for the ICE-L case. In the UM only the central section of the wave cloud with largest vertical velocities is considered. $\Delta q_{\mathrm{t}, \mathrm{f}}$ for the three-dimensional UM simulation and the idealized KiD simulation are comparable in value. This justifies the use of the $\mathrm{KiD}$ model to explore the dependence of $\Delta q_{\mathrm{t}, \mathrm{f}}$ on the upstream thermodynamic profile and the wave period.

The most prominent feature in the variation in $\Delta q_{\mathrm{t}, \mathrm{f}}$ over the sampled part of the phase space is the strong increase in $\Delta_{\text {Lagr }} q_{\mathrm{t}, \mathrm{f}}$ at about a cloud top temperature of $-37^{\circ} \mathrm{C}$, which is due to the onset of homogeneous freezing and hence a large increase in the frozen water content available for sedimentation. For all cloud top temperatures $\Delta_{\mathrm{Lagr}} q_{\mathrm{t}, \mathrm{f}}$ increases towards longer wave periods as expected. These general patterns are consistent for all cloud thicknesses investigated (not shown). The downward moisture transport increase with larger cloud thickness, but the impact of cloud thickness is smaller than that of wave time period and cloud top temperature (not shown). Hence, the discussion in the following focusses on a single cloud thickness, although all sensitivity experiments are included in the formulation of the conceptual model. Consistent with the UM simulations, the parameterization used for heterogeneous freezing impacts the downward moisture transport. Fig. 10b shows the maximum difference between any two simulations with the same wave period, cloud top temperature, and cloud thickness but different heterogeneous freezing parameterizations (20 simula- tions for each combination of wave period, cloud top temperature, and cloud thickness). For the UM simulation the variability is about a factor of 5 larger (colour-filled circle in Fig. 10b), which is mainly due to the low values for the simulation with DM10 and $\epsilon=0.01$. The impact of the parameterization choice is largest for cloud top temperatures just below the onset of homogeneous freezing (see e.g. Fig. 6). In this part of the parameter space $\Delta_{\text {Lagr }} q_{\mathrm{t}}$ varies by up to a factor 10 between simulations with different heterogeneous freezing parameterizations. Differences between simulations with different heterogeneous freezing parameterizations are largest for wave periods larger than $800 \mathrm{~s}$ and cloud top temperatures between $\sim-30$ and $\sim-38^{\circ} \mathrm{C}$.

The downward transport of aerosol $\Delta_{\mathrm{Lagr}} m_{\mathrm{du}}$ is summarized in Fig. 10c and d. $\Delta_{\text {Lagr }} m_{\text {du }}$ and its variation with cloud microphysical parameterization choices are again very similar to the values obtained from the UM simulation (colourfilled circles in Fig. 10c, d). The aerosol downward transport increases, similar to the downward moisture transport, with longer wave periods and towards colder cloud top temperatures. The increase with decreasing cloud top temperature is, however, smoother than for $\Delta_{\text {Lagr }} q_{\mathrm{t}}$. Towards the onset of homogeneous freezing most heterogeneous freezing parameterizations predict that a substantial fraction of dust is activated as INP, and hence there is no step change at the onset of homogeneous freezing. Differences between simulations with different settings in the cloud microphysics are largest 
(a)

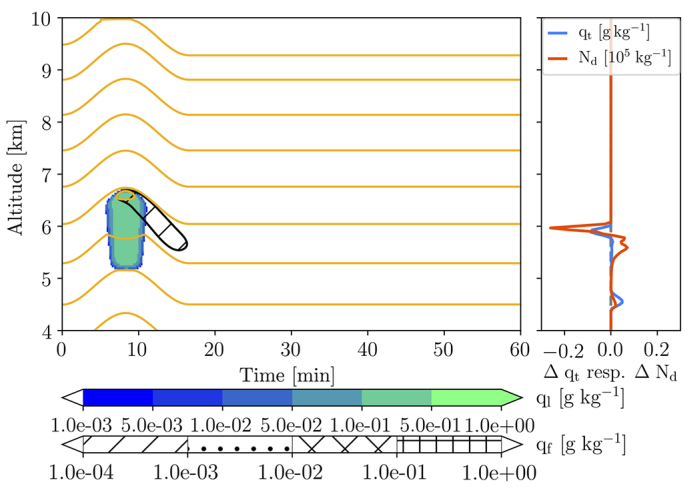

(c)

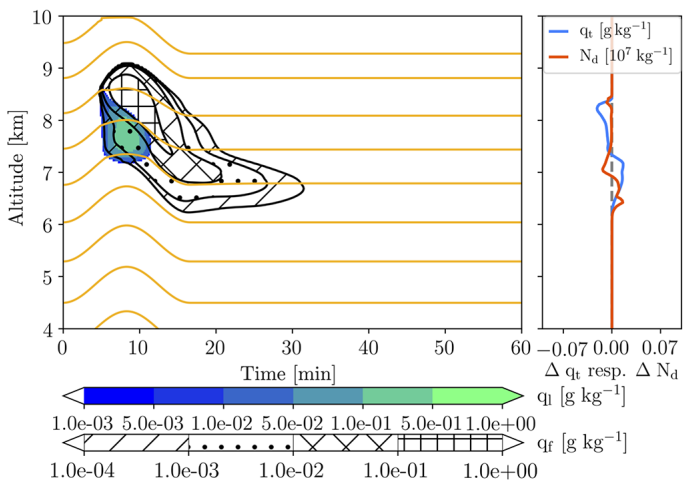

(b)

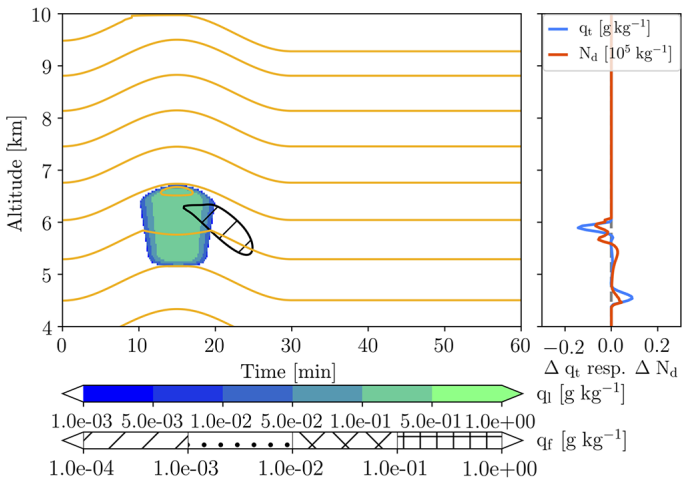

(d)

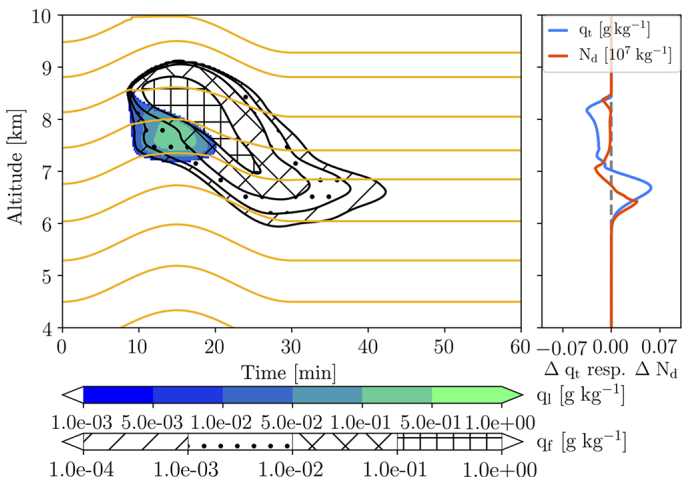

Figure 9. Wave clouds in the KiD model. Simulations of waves with periods of (a, c) $1000 \mathrm{~s}$ and (b, d) $1800 \mathrm{~s}$ are shown. The cloud top temperature is $-24^{\circ} \mathrm{C}$ in (a) and (b) and $-50^{\circ} \mathrm{C}$ in (c) and (d). The cloud droplet mass mixing ratio is indicated by the colour shading, ice and snow mass mixing ratio by the hatched contours, and the isentropes by orange isolines with a spacing of $2 \mathrm{~K}$. The small subpanels show the difference in total water content (light blue line) and the dust number concentration (red line) between the upstream and downstream. Note the different units for the dust number concentration change in (a) and (b) and (c) and (d), respectively.

for wave periods larger than $600 \mathrm{~s}$ and cloud top temperatures between $\sim-19$ and $\sim-28^{\circ} \mathrm{C}$.

A conceptual model of the moisture transport by sedimenting frozen hydrometeors provides insight into the key variables controlling the modification of the moisture profile and may be used to represent these in models with a lower spatial resolution. Similar to previously proposed conceptional models for orographic precipitation (Smith, 1979; Smith and Barstad, 2004; Seifert and Zängl, 2010; Miltenberger et al., 2015), we chose an ansatz based on the consideration of the characteristic timescales of the cloud:

$$
\begin{aligned}
\Delta q_{\mathrm{t}, \mathrm{f}} & =\left(\left(G_{\mathrm{pot}}-G_{\mathrm{nuc}}\right)\left(1-\exp \left(-\frac{\tau_{\mathrm{ic}}}{\tau_{\mathrm{dep}}}\right)\right)+G_{\mathrm{nuc}}\right) \\
& \cdot\left(1-\exp \left(-\frac{\tau_{\mathrm{ic}}}{\tau_{\text {sedi }}}\right)\right) .
\end{aligned}
$$

The first term on the right side of the equation describes how much water is transferred from the gas-phase to frozen condensate due to depositional growth and freezing, while the second term describes the sedimentation of the condensate.
The key variables are (i) the potential condensate $G_{\text {pot }}$, which is the maximum cloud condensate possible given thermodynamic constraints, initial humidity, and vertical displacement; (ii) the in-cloud residence time $\tau_{\text {ic }}$, i.e. the time available for cloud microphysical processes; (iii) the timescale for depositional growth of ice hydrometeors $\tau_{\text {dep }}$; and (iv) the timescale for sedimentation $\tau_{\text {sedi }}$. Note that in contrast to parcel-oriented formulations these timescales refer to the entire cloud and not to individual air parcels. Finally, $G_{\text {nuc }}$ denotes the condensate formed during ice crystal nucleation via homogeneous or heterogeneous freezing. A similar approach has been suggested by Seifert and Zängl (2010) and Miltenberger et al. (2015) for describing the precipitation formation in warm-phase orographic clouds. As we show in the following, all parameters in Eq. (3) can be estimated from the upstream thermodynamic profiles and expected vertical displacement.

As mentioned above, we focus here on the sedimentation flux of frozen hydrometeors. For cloud top temperatures warmer than about $\sim-30^{\circ} \mathrm{C}$, the impact of cloud 
(a)

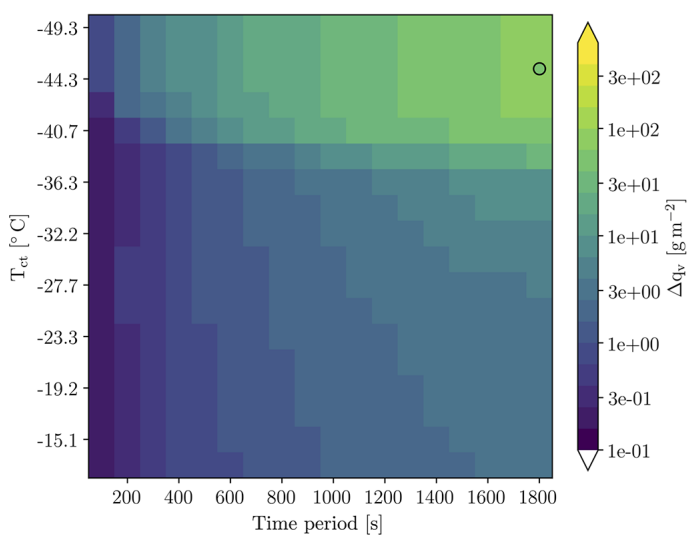

(c)

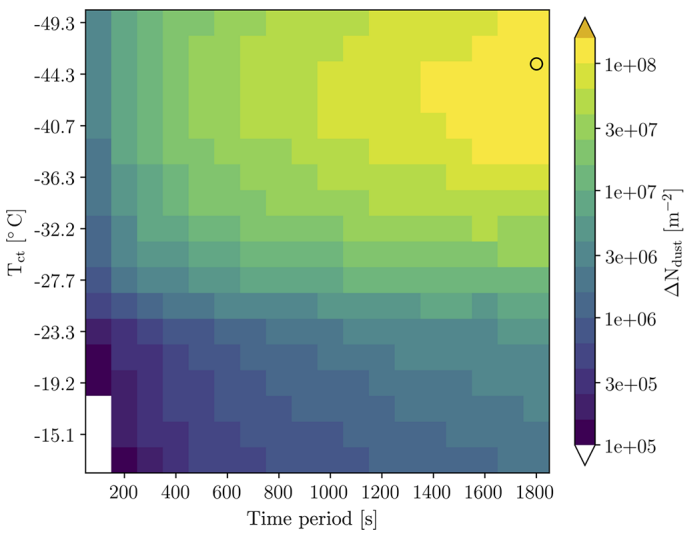

(b)

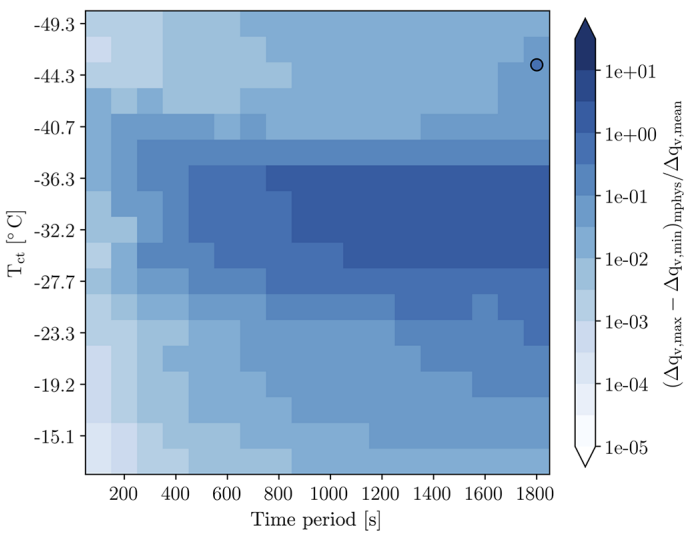

(d)

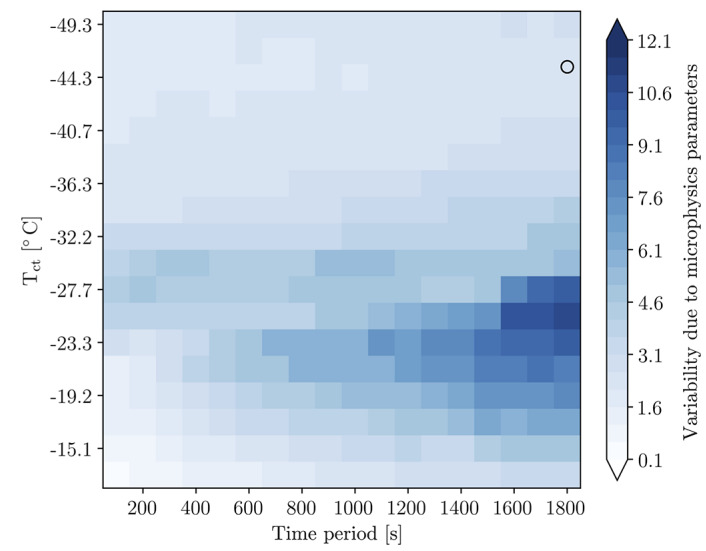

Figure 10. Modification of (a, b) water and (c, d) dust profiles across wave clouds with vertical extent $z_{\mathrm{c}}$ of $2 \mathrm{~km}$ and various cloud top temperatures (ordinate) as well as periods (abscissa). Panels (a) and (c) show the mean value across KiD simulations with different ice nucleation and soluble fraction descriptions. Panels (b) and (d) show the variability resulting from varying the ice nucleation representation and the soluble fraction assumption, i.e. $\left(\left.\Delta_{\text {Lagr }} q_{\mathrm{t}}\right|_{\max }-\left.\Delta_{\mathrm{Lagr}} q_{\mathrm{t}}\right|_{\max }\right) /\left.\Delta_{\text {Lagr }} q_{\mathrm{t}}\right|_{\text {mean }}$. The colour-filled circles indicate the location of the ICE-L case study in the phase space. The colour of the circle shows the value obtained from the UM simulations of the ICE-L cloud.

droplet sedimentation is comparable to or larger than that of frozen hydrometeor sedimentation (Fig. S5b). In contrast to $\Delta_{\text {Lagr }} q_{\mathrm{t}, \mathrm{f}}, \Delta_{\mathrm{Lagr}} q_{\mathrm{t}, 1}$ depends in our set of experiments only on $\tau_{\mathrm{ic}}$. The main reason for this is that a saturation adjustment scheme is used in the UM and KiD model, and only a specific maximum vertical displacement is considered (see Sect. 2.3). Hence, for the following ansatz is chosen for moisture transport by sedimenting cloud droplets:

$\Delta q_{\mathrm{t}, \mathrm{f}}=G_{\mathrm{pot}, 1}\left(1-\exp \left(-\frac{\tau_{\mathrm{ic}}}{\tau_{\text {sedi }, 1}}\right)\right)$.

The potential liquid condensate $G_{\text {pot, }, 1}$, i.e. the difference between the upstream specific humidity and the saturation water content over water at the coldest point along the trajectory, and tau $\mathrm{ic}_{\mathrm{ic}, 1}$ can be estimated using the same procedure as outlined below for $G_{\text {pot }}$ and $\tau_{\text {ic }}$ by considering the saturation mass mixing ratio over water instead of that over ice. The sedimentation timescale $\tau_{\text {sedi, } 1}$ can be estimated by using the profile of $G_{\mathrm{pot}, 1}\left(z_{0}\right)$ together with the typical cloud droplet number concentration (here $70 \mathrm{~cm}^{-3}$ ), the fallspeed-diameter and mass-diameter relationships used in the model, and the cloud depth. Note that despite being significant compared to the frozen hydrometeor sedimentation flux, fluxes are generally very small for temperatures warmer than $-30{ }^{\circ} \mathrm{C}$. In the following, we discuss in detail the estimates for variables in Eq. (3), in line with the focus of the paper.

The potential condensate is the maximum condensate amount that would occur along a wave cloud trajectory if the air parcel's ice water content were in thermodynamic equilibrium, i.e. roughly the difference between the upstream vapour content and the saturation water content over ice at the coldest point along the trajectory. In warm-phase clouds the condensate amount in absence of sedimentation is often close to the potential condensate as a result of fairly small vapour deposition timescales ( $\sim 1 \mathrm{~s})$, as e.g. used in satura- 
tion adjustment parameterizations. However, in mixed- and ice-phase clouds the potential condensate is typically not realized due to the longer timescales for depositional growth (on the order of $1000 \mathrm{~s}$ ). $G_{\text {pot }}$ is not used as a measure of the condensate formed in the cloud but as a "virtual" reservoir species from which condensate can be formed. Along air parcel trajectories $G_{\text {pot }}$ can be directly computed as the difference between the upstream specific humidity and the saturation pressure over ice at the coldest point along the trajectory, if latent heating from phase changes of water are neglected. Using trajectory data from the KiD experiments, the variation in $G_{\text {pot,Lagr }}$ with the wave period and cloud top temperature can be quantified (Fig. 11a). Further $G_{\text {pot }}$ can be computed from the wave amplitude $\mathrm{A}$ and the upstream temperature $t_{0}$, specific humidity $q_{v, 0}$, and pressure $p_{0}$ profiles by assuming dry-adiabatic ascent of the parcel (lapse rate $\gamma$ ) and a hydrostatic balanced atmosphere as follows:

$G_{\text {pot }}\left(z_{0}\right)=\left(q_{v, 0}-q_{i, \text { sat }}\left(t_{0}+A \gamma\right)\right) p_{z_{0}+A}$.

Integrating above equation over all altitudes where $q_{v, 0}>$ $q_{i, \text { sat }}\left(t_{0}+A \gamma\right)$ gives an estimate of $G_{\text {pot }}$, which for our KiD simulations deviates less than $5 \%$ from the Lagrangian estimate shown in Fig. 11a (Fig. S6a).

Another important cloud microphysical variable that will be required for parameterizing the characteristic timescales is the number of ice crystals in each cloud. To characterize the variability across the different clouds, we use only the maximum possible number of ice crystals $n_{\mathrm{i}, \max }$ formed by either homogeneous or heterogeneous freezing. In the Lagrangian data, this is the integral of homogeneous and heterogeneous nucleation rates along the trajectory passing just below cloud top. Figure $11 \mathrm{~b}$ shows that $n_{\mathrm{i} \text {, max,Lagr }}$ depends strongly on cloud top temperature with a major increase around $t_{\mathrm{ct}} \approx-38^{\circ} \mathrm{C}$ reflecting the transition to clouds dominated by homogeneous freezing. For clouds with colder cloud tops there is also a clear dependence on the time period of the wave clouds, reflecting the interaction between the nucleation and growth of newly formed ice crystals (e.g. Kärcher et al., 2006). For the conceptual model, we find that using the heterogeneous parameterization used in the KiD model together with the minimum temperature expected from the maximum vertical displacement gives a reasonable estimate for temperatures warmer than $-38^{\circ} \mathrm{C}$. For colder cloud top temperatures, we use the homogeneous nucleation rate from the DM10 parameterization (consistent with CASIM microphysics) and a correction factor depending on the wave period: $0.932 \cdot \log _{10}(T)+0.228$ for $t_{\mathrm{ct}}<-42.5^{\circ} \mathrm{C}$ and $1.48 \cdot \log _{10}(T)-1.48$ for $t_{\mathrm{ct}}>-42.5^{\circ} \mathrm{C}$. Closely related to the ice crystal number is also the term $G_{\text {nuc }}$ describing the ice crystal mass formed by homogeneous or heterogeneous freezing. $G_{\text {nuc }}$ can be estimated from $n_{\mathrm{i}, \max }$ and a typical particle mass $\overline{q_{i}}$, which can be directly obtain from the KiD simulations: $\overline{q_{i}}=10^{-11.5} \mathrm{~kg} \mathrm{~kg}^{-1}\left(10^{-9.6} \mathrm{~kg} \mathrm{~kg}^{-1}\right)$ for clouds dominated by homogeneous (heterogeneous) freezing.
The in-cloud residence time $\tau_{\text {ic }}$ describes the time available for condensate and precipitation formation (e.g. for warm clouds; Miltenberger et al., 2015). Here, we define $\tau_{\text {ic }}$ as time during which air parcels are supersaturated with respect to ice. This timescale $\tau_{\mathrm{ic}, \text { Lagr }}$ can be directly quantified from the KiD-model air mass trajectories (Fig. 12a) or analytically calculated from the prescribed wave flow and the upstream humidity profile:

$\tau_{\mathrm{ic}}=T \cdot\left(1-\arccos \left(1-0.5 \cdot \eta_{\mathrm{i}, \mathrm{sat}} A \pi^{-1}\right) \pi^{-1}\right)$,

with $\eta_{\mathrm{i} \text {, sat }}$ the vertical displacement required to reach ice saturation. The deviations between this estimate and the Lagrangian metric are less than $5 \%$ (Fig. S6b). From the resulting vertical profile of $\tau_{\mathrm{ic}}$ the largest timescale is selected (only considering cloudy parcels).

The depositional timescale $\tau_{\text {dep }}$ describes the characteristic timescale for the reduction of ice supersaturation for $w=0 \mathrm{~m} \mathrm{~s}^{-1}$ and an ice crystal population characterized by the number concentration $n_{\mathrm{i}}$ and mean ice particle diameter $d_{\mathrm{i}}$. The concept of describing depositional growth of ice crystals with a characteristic timescale $\tau_{\text {dep }}$ is frequently used in literature and cloud microphysical parameterizations (e.g. Khvorostyanov, 1995): $\tau_{\mathrm{dep}}=\left(g n_{\mathrm{i}} d_{\mathrm{i}} c_{\mathrm{i}} f\right)^{-1}$, where $g=$ $4 \pi \cdot\left(L_{\text {ed }}^{2}\left(K_{t} R_{\mathrm{d}} t^{2}\right)^{-1}+R_{\mathrm{d}} t\left(D_{\mathrm{vtp}} e_{\mathrm{s}, \mathrm{i}}\right)^{-1}\right)^{-1}, L_{\mathrm{ed}}$ is the latent heat of sublimation, $K_{t}$ is the heat conductivity, $R_{\mathrm{d}}$ is the specific gas constant for dry air, $D_{\mathrm{vtp}}$ is the diffusivity of water vapour, $e_{\mathrm{s}, \mathrm{i}}$ is the saturation vapour pressure over ice, $c_{\mathrm{i}}$ is the capacitance of the ice crystals, and $f$ is a ventilation factor. This concept needs to be extended to a single characteristic timescale for the entire cloud. To estimate this timescale we again utilize the KiD simulations. The cloud-scale deposition timescale can be estimated from the integrated deposition $D$ and freezing rates $G_{\text {nuc }}$ as well as $\tau_{\text {ic }}$ according to $\tau_{\text {dep,Lagr }}=\tau_{\text {ic,Lagr }}\left(\log \left(1-D\left(G_{\text {pot }}-G_{\text {nuc }}\right)^{-1}\right)^{-1}\right.$. The resulting estimates are shown in Fig. 12b. Immediately obvious is an inverse relation to the ice crystal number concentration, as expected from air parcel considerations, but this is not the sole determinant. In order to estimate $\tau_{\text {dep }}$ from the a priori known parameters, i.e. upstream profiles and vertical displacement, we determined the following least-square fits to the KiD model data (Fig. S6c):

$$
\tau_{\mathrm{dep}}=\left\{\begin{array}{l}
5.29 \times 10^{10} \cdot n_{\mathrm{i}}^{-1.94} \cdot T^{-0.558} \cdot z_{\mathrm{c}}^{0.539} \\
\quad \text { if } t_{\mathrm{ct}} \geq-34.25^{\circ} \mathrm{C} \\
1.71 \times 10^{7} \cdot n_{\mathrm{i}}^{-0.764} \cdot T^{-0.716} \cdot z_{\mathrm{c}}^{0.696} \cdot\left(n_{\mathrm{i}} T\right)^{0.0566} \\
\quad \text { if }-44.3^{\circ} \mathrm{C}<t_{\mathrm{ct}}<-34.25^{\circ} \mathrm{C} \\
1.34 \times 10^{7} \cdot n_{\mathrm{i}}^{-0.749} \cdot T^{-0.271} \cdot z_{\mathrm{c}}^{0.576} \\
\quad \text { if } t_{\mathrm{ct}} \leq-44.3^{\circ} \mathrm{C} .
\end{array}\right.
$$

The subdivision is necessary due to the fundamentally different behaviour in the parts of the parameter space dominated by homogeneous and heterogeneous freezing.

Finally, the sedimentation timescale needs to be determined, for which we use the same approach as for the deposition timescale, i.e. diagnosing a cloud-wide timescale 
(a)

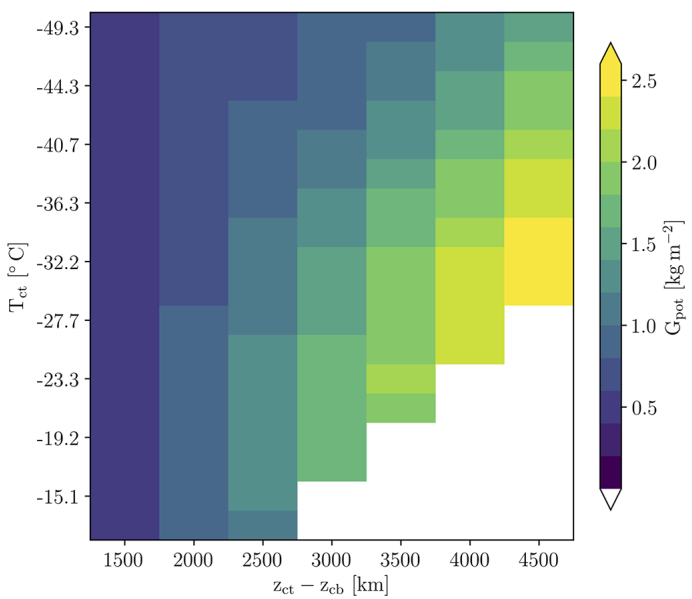

(b)

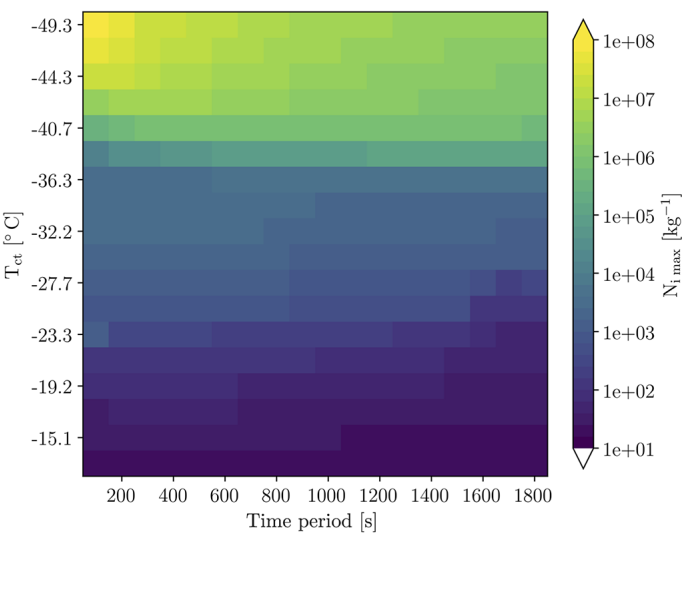

Figure 11. (a) Potential condensate $G_{\text {pot }}$ as a function of cloud thickness and cloud top temperature. (b) Maximum ice crystal number concentration $n_{\mathrm{i}, \text { max,Lagr }}$ as a function of wave period and cloud top temperature for clouds with a thickness of $2 \mathrm{~km}$. $n_{\mathrm{i}, \text { max,Lagr }}$ is the maximum integrated ice crystal formation rate, including homogeneous and heterogeneous freezing, along any trajectory through the wave cloud.

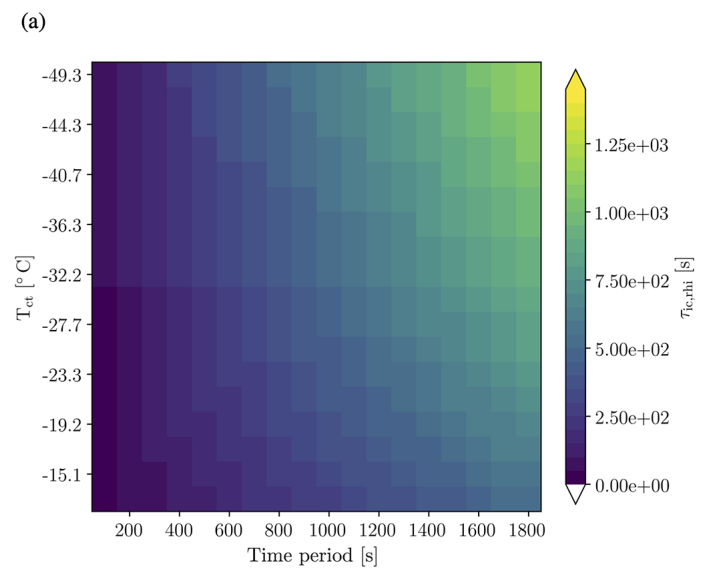

(b)

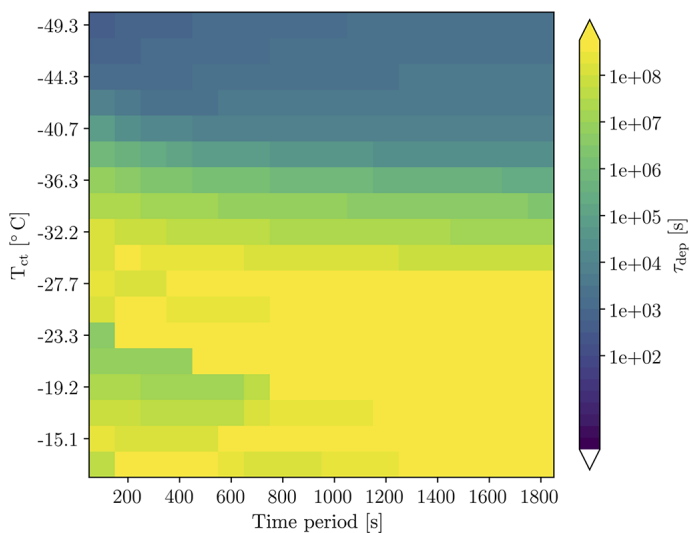

(c)

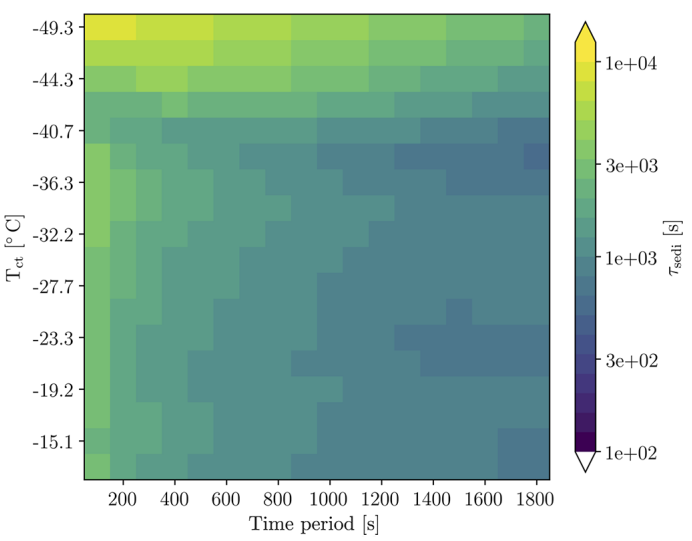

Figure 12. Lagrangian estimates of (a) the in-cloud residence timescale $\tau_{\text {ic }}$, (b) the deposition timescale $\tau_{\text {dep }}$, and (c) the sedimentation timescale $\tau_{\text {sedi }}$. Results are shown for simulations with a cloud thickness of $2 \mathrm{~km}$. 
from the KiD model and constructing a statistical model. The timescale is estimated from the KiD model according to $\tau_{\text {sedi }, L}=\tau_{\text {ic }, L}\left(\log \left(1-\Delta q_{\text {sedi }}\left(D+G_{\text {nuc }}\right)^{-1}\right)^{-1}\right.$. The results are shown in Fig. 12c. The sedimentation velocity in the KiD model is described using a prescribed diameter-fallspeed relation. Consistently, the $\tau_{\text {sedi }}$ increases for clouds with larger $n_{\mathrm{i}}$. In addition to this information, we find that it is necessary to incorporate information on the time period and cloud thickness in the statistical model likely due to their impact on the cloud microphysical evolution (Fig. S6d):

$$
\tau_{\text {sedi }}=\left\{\begin{array}{c}
4.01 \times 10^{3} \cdot n_{\mathrm{i}}^{-0.0185 \cdot T-0.242 z_{\mathrm{c}}-0.449} \\
\cdot T^{0.0253 t_{\mathrm{ct}}-0.467}, \text { if } t_{\mathrm{ct}} \geq-32 .{ }^{\circ} \mathrm{C} \\
4.26 \times 10^{4} \cdot n_{\mathrm{i}}^{-0.0507 \cdot T-0.326 z_{\mathrm{c}}+1.03} \\
\cdot T^{0.663 t_{\mathrm{ct}}-2.43}, \\
\text { if }-38.5^{\circ} \mathrm{C}<t_{\mathrm{ct}}<-32 .{ }^{\circ} \mathrm{C} \\
3.06 \times 10^{4} \cdot n_{\mathrm{i}}^{0.385 \cdot T-0.0613 z_{\mathrm{c}}-0.500} \\
\cdot T^{-0.143 t_{\mathrm{ct}}-1.65}, \text { if } t_{\mathrm{ct}} \leq-38.5^{\circ} \mathrm{C} .
\end{array}\right.
$$

By using Eqs. (3) to (8) with the described approximation of $n_{\mathrm{i}, \mathrm{max}}$, the total downward moisture transport by sedimentation can be computed based on the upstream dust concentration, the upstream profiles of temperature, humidity, and pressure, and the maximum vertical displacement. The parameterized $\Delta q_{\mathrm{t}}$ is shown in Fig. 13a. Comparing this figure with the results from the full KiD model (Fig. 10a) shows very similar dependencies on wave period and cloud top temperature. Note that Fig. 10a shows the average $\Delta q_{\mathrm{t}}$ from simulations with different heterogeneous freezing parameterizations, while Fig. 13a shows data only for simulations with DM10 - hence the differences in absolute values. The absolute values from the conceptual model agree well with the simulations from the full KiD model with discrepancies mostly smaller than $30 \%$ (Fig. 13b, Fig. S7).

\section{Conclusions}

Orographic wave clouds impact atmospheric flow by interacting with radiative fluxes and by modifying the moisture and aerosol profiles. Furthermore, due to the laminar flow they are ideal natural laboratories to explore cloud microphysical processes along the wind (time) direction. Here, we compare simulations with the Unified Model (UM) including the recently developed Cloud-Aerosol Interacting Microphysics (CASIM) module to observations from the ICE-L measurement campaign, which took place in 2007 over the mountain states of the US.

High-resolution simulations with the UM capture the thermodynamic structure and vertical velocity field very well with deviations of less than $1 \mathrm{~K}$ for air temperature, $0.2 \mathrm{~g} \mathrm{~kg}^{-1}$ for specific humidity and $1 \mathrm{~m} \mathrm{~s}^{-1}$ for vertical velocity. The overall cloud microphysical structure of the cloud is similar to the observations, although there are significant differences in the impact of homogeneous freezing, the extent of ice tail of the cloud, and the size distribution. Some of the differences could be explained by an overestimation of the vertical displacement in the model, but problems with the cloud microphysical parameterization can also not be excluded. More detailed information on the 3D wind field should be considered in future studies. Several heterogeneous freezing parameterizations have been proposed in recent years, and we explicitly tested their impact on the cloud structure. Most tested heterogeneous freezing parameterizations gave very similar results. The main difference between simulations with the different schemes is the vertical gradient of ice crystal number concentration in the updraught region of the cloud; all other investigated cloud properties display only a very small sensitivity. For all tested parameterizations, except Atkinson et al. (2013), the vertical gradient of the ice crystal number concentration is consistent with the observations given the uncertainty in observations and their representativity. The best agreement is obtained for simulations with DeMott et al. (2010), followed by those using DeMott et al. (2015) and Tobo et al. (2013). As CASIM explicitly models dust particles in liquid and ice hydrometeors, we also tested the impact of using dust also incorporated in liquid droplets for heterogeneous freezing and of prescribing different soluble fractions on dust aerosols. Both made only very little impact on the cloud microphysical structure. Despite the well-captured thermodynamic conditions and flow dynamics, vigorous conclusion about link between ice crystal number concentration and upstream aerosol, in particular the temperature dependence of heterogeneous freezing, are difficult to arrive at. For this purpose, future campaigns need to provide a better characterization of the upstream profiles of aerosols and their temporal evolution as well as observations of the full ice crystal size distribution (here limited to particles larger than $50 \mu \mathrm{m}$ ). The advance in measurement techniques over the past years allows these requirements to be met in future field campaigns.

The simulations were further used to investigate the modification of moisture and aerosol profiles by the sedimentation of hydrometeors in the wave cloud. The latter was only possible due to the novel capabilities of the CASIM module. Lagrangian estimates suggest a different vertical structure of the aerosol and moisture changes, with those for aerosols concentrated at cloud top and cloud base. However, the fairly small changes in the profiles $\left(<0.1 \mathrm{~g} \mathrm{~kg}^{-1}\right.$ for moisture, $<0.1 \mathrm{~cm}^{-3}$ for aerosol) prevent the constraint of the sedimentation fluxes with observations.

Two-dimensional, idealized simulations were developed to further investigate the parameter space, with a particular focus on the dependence of the moisture and aerosol sedimentation fluxes on the cloud geometry, i.e. the wavelength, cloud top temperature, and cloud thickness. The simulations are confined to a specific vertical displacement of roughly $900 \mathrm{~m}$ and time periods of the wave motion between 100 and $1800 \mathrm{~s}$. From the few climatological studies available the lat- 
(a)

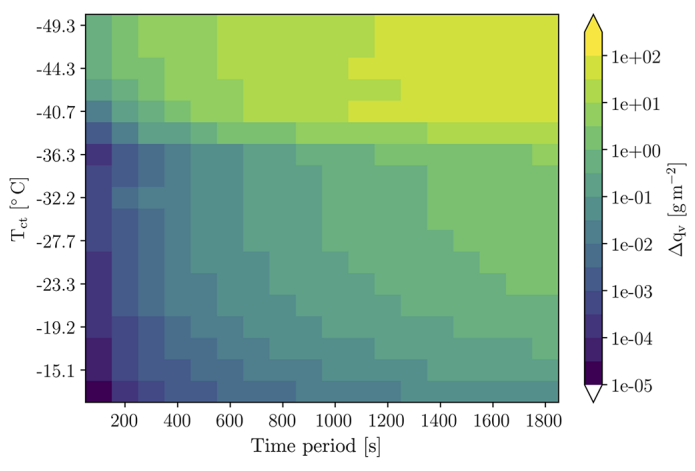

(b)

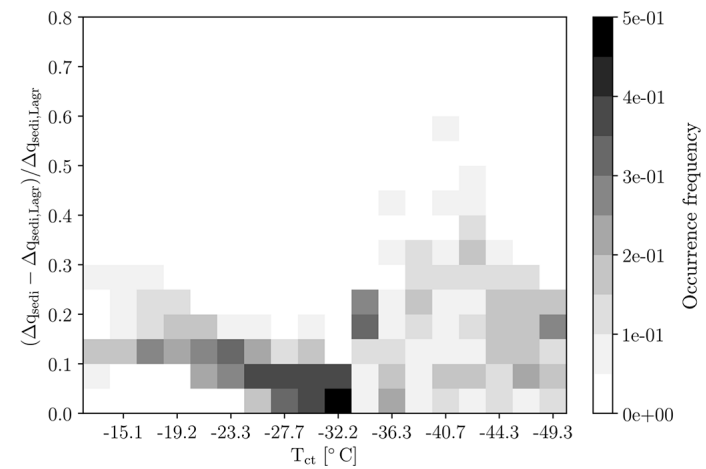

Figure 13. (a) Total downward transport of water predicted using Eqs. (3) to (8) across wave clouds with vertical extent $z_{\mathrm{c}}$ of $2 \mathrm{~m}$, the DM10 heterogeneous freezing parameterization, and various cloud top temperatures (ordinate) as well as periods (abscissa). (b) Normalized difference between $\Delta q_{\mathrm{t}}$ predicted by the conceptual model and the full KiD model for different cloud top temperatures. The data shown in (b) include the full simulations set with all cloud top temperature, wavelength, and cloud thickness specified in Sect. 2.3.

ter is roughly what is expected for isolated cap clouds or lee wave clouds. It would be interesting to extend the analysis to different vertical displacements, i.e. larger wave amplitudes. While larger (or smaller) wave amplitudes would modify the condensate formed in the cloud, we do not expect a major impact on the timescale approach discussed above. However, some of the empirical fitting parameters may change as a result of the establishment of different size distributions. Extending the analysis to different vertical displacements is beyond the scope of the present study. The sensitivity to the heterogeneous freezing parameterization is found to be largest for wave periods larger than $1000 \mathrm{~s}$ and cloud top temperatures between -30 and $-40^{\circ} \mathrm{C}$. The modifications of the moisture and aerosol profiles are largest for clouds with long wave periods and cloud top temperatures colder than $-40^{\circ} \mathrm{C}$. The Lagrangian change of water content is on the order of $0.1 \mathrm{~g} \mathrm{~kg}^{-1}$ and that of dust number concentration on the order of $0.1 \mathrm{~cm}^{-3}$, i.e. comparable to the results obtained for the ICE-L case. The modification of the water and aerosol profiles depends also on the chosen parameterization of homogeneous freezing and the parameterization of hydrometeor fallspeeds. The impact of altering these parameterizations has not been tested in the present study, but should be investigated in future work. Based on the idealized KiD simulations we develop a conceptual model that depends on the potential condensate, in-cloud residence timescale, deposition timescale, and sedimentation timescale. Lagrangian estimates of the last two timescales are used to derive an approximation of the timescales, while the other necessary variables can be calculated analytically from the upstream thermodynamic and aerosol profiles. The resulting model captures the variability in the downward transport of moisture by sedimenting hydrometeors in a large part of the phase space with deviations less than $30 \%$ for almost all parameter combinations. The error is somewhat larger for cloud top temperatures between -36 and $-42^{\circ} \mathrm{C}$, i.e. in the transition region between clouds dominated by heterogeneous and those dominated by homogeneous freezing.

The analysis in the present paper suggests that UMCASIM framework can reasonably capture some key components of mixed-phase orographic clouds such as the vertical velocity structure, the coexistence of liquid and ice particles, and the existence of regions dominated by ice crystals formed by heterogeneous or homogeneous freezing. However, there are some deviations between the modelled and observed thermodynamic conditions and cloud properties. These deviations maybe do to spatio-temporal variations in the upstream thermodynamic fields and the structure of the wave, which are not well characterized in the available observational data. The deviations may also result from uncertainty in the regional model predictions due initial and boundary condition uncertainty. And finally errors in the model representation of dynamics and sub-grid-scale processes may be the source of the differences between observations and model results. It is important to properly explore all these options, which is beyond the scope of the present paper but will be addressed in future work. As the UM-CASIM simulations can currently not be vigorously constrained with observations, there is also some uncertainty as to the accuracy of the idealized, twodimensional simulations and the derived conceptual model. This pertains mainly to the formulation and absolute values of the timescales.

While it is not possible to constrain the downward transport of aerosol or water vapour with the observations available from ICE-L, future aircraft campaigns targeting orographic wave clouds would be useful to quantify these important processes and provide constraints on aerosol transport processes also for more comprehensive aerosol models such as UK Chemistry and Aerosol Model (UKCA; e.g. Planche et al., 2017). Any future campaign should aim at a better characterization of the upstream and downstream moisture and aerosol profiles including their temporal evolution and a 
characterization of the 3D velocity field. The idealized simulations show that clouds with wave periods larger than $1000 \mathrm{~s}$ and cloud top temperatures between $\sim-19$ and $\sim-28^{\circ} \mathrm{C}$ $\left(\sim-30\right.$ and $\left.\sim-38^{\circ} \mathrm{C}\right)$ show a large sensitivity of the downward aerosol (humidity) transport to choices in the cloud microphysical parameterization. Similarly, differences between simulations with different heterogeneous freezing parameterizations are largest for wave periods larger than $800 \mathrm{~s}$ and cloud top temperatures between $\sim-30$ and $\sim-38^{\circ} \mathrm{C}$. These regions of the phase space therefore would be interesting to target in future observational campaigns.

Code availability. The source code of the KiD-A model version used here and the namelist files are archived in a private directory on https://bitbucket.org (https://bitbucket.org/amiltenberger/kida_ model_with_taubin_casim_icel, last access: 3 July 2020). Access will be granted by the authors on request.

Data availability. Model data are stored on the tape archive provided by JASMIN (http://www.jasmin.ac.uk/, last access: 3 July 2020) service and can be provided by the author on request. Most observational data are available from https://www.eol. ucar.edu/field_projects/ice-1 (NCAR Earth Observing Laboratory, 2020).

Supplement. The supplement related to this article is available online at: https://doi.org/10.5194/acp-20-7979-2020-supplement.

Author contributions. All authors contributed to the development of the concepts and ideas presented in this paper. AHH developed the KiD model. AKM developed the model set-up with major contributions from PRF for the UM simulations and AHH for the KiD set-up. PRF and AJH provided expertise on the observational data. All model simulations and the subsequent data analysis were performed by AKM. She also wrote the majority of the paper with input and comments from all coauthors.

Competing interests. The authors declare that they have no conflict of interest.

Acknowledgements. We thank Ben Shipway and Jonathan Wilkinson for designing CASIM and incorporating it into the UM model. Annette K. Miltenberger also thanks Axel Seifert for insightful discussions on the characteristic timescales of ice-phase orographic clouds. We acknowledge the efforts of the ICE-L team for obtaining the observational data. Further, we acknowledge use of the Monsoon2 system, a collaborative facility supplied under the Joint Weather and Climate Research Programme, a strategic partnership between the Met Office and the Natural Environment Research Council. All KiD simulations and data analysis were performed on JASMIN, the UK collaborative data analysis environment (http: //jasmin.ac.uk). Annette K. Miltenberger acknowledges support by Deutsche Forschungsgemeinde (DFG) as part of the Transregional Collaborative Research Center SFB/TRR 165 "Waves to Weather".

Financial support. This research has been supported by the Deutsche Forschungsgemeinde (DFG) (Transregional Collaborative Research Center SFB/TRR 165 "Waves to Weather")

Review statement. This paper was edited by Xiaohong Liu and reviewed by Minghui Diao and one anonymous referee.

\section{References}

Abdul-Razzak, H. and Ghan, S. J.: A parameterization of aerosol activation. 2. Multiple aerosol types, J. Geophys. Res., 105, 68376844, 2000.

Aranami, K., Zerroukat, M., and Wood, N.: Mixing properties of SLICE and other mass-conservative semi-Lagrangian schemes, Q. J. Roy. Meteor. Soc., 140, 2084-2089, https://doi.org/10.1002/qj.2268, 2014.

Aranami, K., Davies, T., and Wood, N.: A mass restoration scheme for limited-area models with semi-Lagrangian advection, Q. J. Roy. Meteor. Soc., 141, 1795-1803, https://doi.org/10.1002/qj.2482, 2015.

Atkinson, J. D., Murray, B. J., Woodhouse, M. T., Whale, T. F., Baustian, K. J., Carslaw, K. S., Dobbie, S., O’Sullivan, D., and Malkin, T. L.: The importance of feldspar for ice nucleation by mineral dust in mixed-phase clouds, Nature, 498, 355-358, https://doi.org/10.1038/nature12278, 2013.

Baker, B. A. and Lawson, R. P.: In Situ Observations of the Microphysical Properties of Wave, Cirrus, and Anvil Clouds. Part I: Wave Clouds, J. Atmos. Sci., 63, 3160-3185, https://doi.org/10.1175/JAS3802.1, 2006.

Bergeron, T.: On the physics of cloud and precipitation, Mémoire présenté a l'Association de Météorologie de l'U.G.G.I. Lissabon Septembre 1933, Paris Imprimerie Paul Dupont, 1935.

Clark, P., Roberts, N., Lean, H., Ballard, S. P., and CharltonPerez, C.: Convection-permitting models: a step-change in rainfall forecasting, Meteorol. Appl., 23, 165-181, https://doi.org/10.1002/met.1538, 2016.

Colle, B. A. and Zeng, Y.: Bulk microphysical sensitivities within the MM5 for orographic precipitation. Part I: The Sierra 1986 event, Mon. Weather Rev., 132, 2780-2801, 2004.

Cotton, R. J. and Field, P. R.: Ice nucleation characteristics of an isolated wave cloud, Q. J. Roy. Meteor. Soc., 128, 2417-2437, https://doi.org/10.1256/qj.01.150, 2002.

D’Alessandro, J. J., Diao, M., Wu, C., Liu, X., Jensen, J. B., and Stephens, B. B.: Cloud phase and relative humidity distributions over the Southern Ocean in austral summer based on in situ observations and CAM5 simulations, J. Climate, 32, 2781-2805, https://doi.org/10.1175/JCLI-D-18-0232.1, 2019.

Dearden, C., Connolly, P. J., Choularton, T., Field, P. R., and Heymsfield, A. J.: Factors influencing ice formation and growth in simulations of a mixed-phase wave cloud, J. Adv. Model. Earth Sy., 4, https://doi.org/10.1029/2012MS000163, 2012. 
DeMott, P. J., Prenni, A. J., Liu, X., Kreidenweis, S. M., Petters, M. D., Twohy, C. H., Richardson, M. S., Eidhammer, T., and Rogers, D. C.: Predicting global atmospheric ice nuclei distributions and their impacts on climate, P. Natl. Acad. Sci. USA, 107, 11217-11222, https://doi.org/10.1073/pnas.0910818107, 2010.

DeMott, P. J., Prenni, A. J., McMeeking, G. R., Sullivan, R. C., Petters, M. D., Tobo, Y., Niemand, M., Möhler, O., Snider, J. R., Wang, Z., and Kreidenweis, S. M.: Integrating laboratory and field data to quantify the immersion freezing ice nucleation activity of mineral dust particles, Atmos. Chem. Phys., 15, 393-409, https://doi.org/10.5194/acp-15-393-2015, 2015.

Eidhammer, T., DeMott, P. J., Prenni, A. J., Petters, M. D., Twohy, C. H., Rogers, D. C., Stith, J., Heymsfield, A., Wang, Z., Pratt, K. A., Prather, K. A., Murphy, S. M., Seinfeld, J. H., Subramanian, R., and Kreidenweis, S. M.: Ice Initiation by Aerosol Particles: Measured and Predicted Ice Nuclei Concentrations versus Measured Ice Crystal Concentrations in an Orographic Wave Cloud, J. Atmos. Sci., 67, 2417-2436, https://doi.org/10.1175/2010JAS3266.1, 2010.

Field, P. R., Cotton, R. J., Johnson, D., Noone, K., Glantz, P., Kaye, P. H., Hirst, E., Greenaway, R. S., Jost, C., Gabriel, R., Reiner, T., Andreae, M., Saunders, C. P. R., Archer, A., Choularton, T., Smith, M., Brooks, B., Hoell, C., Bandy, B., and Heymsfield, A.: Ice nucleation in orographic wave clouds: Measurements made during INTACC, Q. J. Roy. Meteor. Soc., 127, 1493-1512, https://doi.org/10.1002/qj.49712757502, 2001.

Field, P. R., Heymsfield, A. J., Shipway, B. J., DeMott, P. J., Pratt, K. A., Rogers, D. C., Stith, J., and Prather, K. A.: Ice in clouds experiment-layer clouds. Part II: Testing characteristics of heteorogeneous ice formation in lee wave clouds, J. Atmos. Sci., 69, 1066-1079, 2012.

Findeisen, W.: Colloidal meteorological processes in the formation of precipitation, Meteorol. Z., 55, 121-133, https://doi.org/10.1127/metz/2015/0675, 2015.

Fletcher, N. H.: Time lag in ice crystal nucleation in the atmosphere. Part 2: Theoretical, Bulletin de l'observatoire du puy de dome, 1, 11-18, 1958.

Grubisic, V. and Billings, B. J.: Climatology of the Sierra Nevada Mountain-Wave Events, Mon. Weather Rev., 136, 757-768, https://doi.org/10.1175/2007MWR1902.1, 2008.

Halliwell, C.: Subgrid turbulence scheme, Unified model documentation paper 028, Met Office, Exeter, UK, 2015.

Hande, L. B. and Hoose, C.: Partitioning the primary ice formation modes in large eddy simulations of mixed-phase clouds, Atmos. Chem. Phys., 17, 14105-14118, https://doi.org/10.5194/acp-1714105-2017, 2017.

Henneberg, O., Henneberger, J., and Lohmann, U.: Formation and development of orographic mixed-phase clouds, J. Atmos. Sci., 74, 3703-3724, https://doi.org/10.1175/JAS-D-16-0348.1, 2017.

Heymsfield, A. J. and Miloshevich, L. M.: Homogeneous Ice Nucleation and Supercooled Liquid Water in Orographic Wave Clouds, J. Atmos. Sci., 50, 2335-2353, https://doi.org/10.1175/15200469(1993)050<2335:HINASL>2.0.CO;2, 1993.

Heymsfield, A. J., Field, P. R., Bailey, M., Rogers, D., Stith, J., Twohy, C., Wang, Z., and Haimov, S.: Ice in clouds experimentlayer clouds. Part I: Ice growth rates derived from lenticular wave cloud penetrations, J. Atmos. Sci., 68, 2628-2654, 2011.

Hill, A. A., Shipway, B. J., and Boutle, I. A.: How sensitive are aerosol-precipitation interactions to the warm rain representation?, J. Adv. Model. Earth Sy., 7, 987-1004, https://doi.org/10.1002/2014ms000422, 2015.

Houze, R. A. J.: Orographic effects on precipitating clouds, Rev. Geophys., 50, RG0001, https://doi.org/10.1029/2011RG000365, 2012.

Jeffery, C. A. and Austin, P. H.: Homogeneous nucleation of supercooled water: Results from a new equation of state, J. Geophys. Res.-Atmos., 102, 25269-25279, https://doi.org/10.1029/97JD02243, 1997.

Jiang, Q. and Smith, R. B.: Cloud Timescales and Orographic Precipitation, J. Atmos. Sci., 60, 1543-1559, 2003.

Johnson, J. S., Cui, Z., Lee, L. A., Gosling, J. P., Blyth, A. M., and Carslaw, K. S.: Evaluating uncertainty in convective cloud microphysics using statistical emulation, J. Adv. Model. Earth Sy., 7, 162-187, https://doi.org/10.1002/2014MS000383, 2015.

Joos, H., Spichtinger, P., Lohmann, U., Gayet, J.-F., and Minikin, A.: Orographic cirrus in the global climate model ECHAM5, J. Geophys. Res., 113, D18205, https://doi.org/10.1029/2007JD009605, 2008.

Joos, H., Spichtinger, P., Reutter, P., and Fusina, F.: Influence of heterogeneous freezing on the microphysical and radiative properties of orographic cirrus clouds, Atmos. Chem. Phys., 14, 68356852, https://doi.org/10.5194/acp-14-6835-2014, 2014.

Kanji, Z. A., Ladino, L. A., Wex, H., Boose, Y., BurkertKohn, M., Cziczo, D. J., and Krämer, M.: Overview of ice nucleating particles, Meteorol. Monogr., 58, 1.1-1.33, https://doi.org/10.1175/AMSMONOGRAPHS-D-16-0006.1, 2017.

Kärcher, B., Hendricks, J., and Lohmann, U.: Physically based parameterization of cirrus cloud formation for use in global atmospheric models, J. Geophys. Res., 111, D01205, https://doi.org/10.1029/2005JD006219, 2006.

Khvorostyanov, V. I.: Mesoscale processes of cloud formation, cloud-radiation interaction, and their modelling with explicit cloud microphysics, Atmos. Res., 39, 1-67, 1995.

Meyers, M. P., DeMott, P. J., and Cotton, W. R.: New primary icenucleation parameterizations in an explicit cloud model, J. Appl. Meteorol., 31, 708-721, 1992.

Miltenberger, A. K., Seifert, A., Joos, H., and Wernli, H.: Scaling relation for warm-phase orographic precipitation - A Lagrangian analysis for 2D mountains, Q. J. Roy. Meteor. Soc., 141, 21852198, https://doi.org/10.1002/qj.2514, 2015.

Miltenberger, A. K., Field, P. R., Hill, A. A., Rosenberg, P., Shipway, B. J., Wilkinson, J. M., Scovell, R., and Blyth, A. M.: Aerosol-cloud interactions in mixed-phase convective clouds Part 1: Aerosol perturbations, Atmos. Chem. Phys., 18, 3119 3145, https://doi.org/10.5194/acp-18-3119-2018, 2018.

Muhlbauer, A. and Lohmann, U.: Sensitivity Studies of Aerosol-Cloud Interactions in Mixed-Phase Orographic Precipitation, J. Atmos. Sci., 66, 2517-2538, https://doi.org/10.1175/2009JAS3001.1, 2009.

Muhlbauer, A., Hashino, T., Xue, L., Teller, A., Lohmann, U., Rasmussen, R. M., Geresdi, I., and Pan, Z.: Intercomparison of aerosol-cloud-precipitation interactions in stratiform orographic mixed-phase clouds, Atmos. Chem. Phys., 10, 81738196, https://doi.org/10.5194/acp-10-8173-2010, 2010.

NCAR Earth Observing Laboratory: Description and field catalogy for the ICE-L campaign, UCAR, Boulder, USA, avail- 
able at: https://www.eol.ucar.edu/field_projects/ice-1, last access: 3 July 2020.

Niemand, M., Möhler, O., Vogel, B., Vogel, H., Hoose, C., Connolly, P., Klein, H., Bingemer, H., DeMott, P., Skrotzki, J., and Leisner, T.: A particle-surface-area-based parameterization of immersion freezing on desert dust particles, J. Atmos. Sci., 69, 3077-3092, https://doi.org/10.1175/JAS-D-11-0249.1, 2012.

Petters, M. D. and Wright, T. P.: Revisiting ice nucleation from precipitation samples, Geophys. Res. Lett., 42, 8758-8766, https://doi.org/10.1002/2015GL065733, 2015.

Planche, C., Mann, G. W., Carslaw, K. S., Dalvi, M., Marsham, J. H., and Field, P. R.: Spatial and temporal CCN variations in convection-permitting aerosol microphysics simulations in an idealised marine tropical domain, Atmos. Chem. Phys., 17, 3371-3384, https://doi.org/10.5194/acp-17-3371-2017, 2017.

Pousse-Nottelmann, S., Zubler, E. M., and Lohmann, U.: Microphysical processing of aerosol particles in orographic clouds, Atmos. Chem. Phys., 15, 9217-9236, https://doi.org/10.5194/acp15-9217-2015, 2015.

Pratt, K. A., Twohy, C. H., Murphy, S. M., Mofet, R. C., Heymsfield, A. J., Gaston, C. J., DeMott, P. J., Field, P. R., Henn, T. R., Rogers, D. C., Gilles, M. K., Seinfeld, J. H., and Prather, K. A.: Observation of playa salts as nuclei in orographic wave clouds, J. Geophys. Res., 115, D15301, https://doi.org/10.1029/2009JD013606, 2010.

Sawyer, J. S.: The physical and dynamical problems of orographic rain, Weather, 11, 375-381, 1956.

Seifert, A. and Zängl, G.: Scaling relations in warmrain orographic precipitation, Meteorol. Z., 19, 1-10, https://doi.org/10.1127/0941-2948/2010/0474, 2010.

Shipway, B. J. and Hill, A. A.: Diagnosis of systematic differences between multiple parametrizations of warm rain microphysics using a kinematic framework, Q. J. Roy. Meteor. Soc., 138, 2196-2211, https://doi.org/10.1002/qj.1913, 2012.

Smith, R. B.: The influence of mountains on the atmosphere, Adv. Geosci., 21, 87-230, 1979.

Smith, R. B. and Barstad, I.: A Linear Theory of Orographic Precipitation, J. Atmos. Sci., 61, 1377-1391, 2004.

Smith, S. A., Field, P. R., Vosper, S. B., Shipway, B. J., and Hill, A. A.: A parameterization of sub-grid orographic rain enhancement via the seeder-feeder effect, Q. J. Roy. Meteor. Soc., https://doi.org/10.1002/qj.2637, 2015.

Sprenger, M. and Wernli, H.: The Lagrangian analysis tool LAGRANTO - version 2.0, Geosci. Model Dev., 8, 2569-2586, https://doi.org/10.5194/gmd-8-2569-2015, 2015.

Stevens, B. and Seifert, A.: Understanding macrophysical outcomes of microphysical choices in simulations of shallow cumulus convection, J. Meteorol. Soc. Jpn., 86A, 143-162, 2008.

Stevens, R. G., Loewe, K., Dearden, C., Dimitrelos, A., Possner, A., Eirund, G. K., Raatikainen, T., Hill, A. A., Shipway, B. J., Wilkinson, J., Romakkaniemi, S., Tonttila, J., Laaksonen, A., Korhonen, H., Connolly, P., Lohmann, U., Hoose, C., Ekman, A. M. L., Carslaw, K. S., and Field, P. R.: A model intercomparison of CCN-limited tenuous clouds in the high Arctic, Atmos. Chem. Phys., 18, 11041-11071, https://doi.org/10.5194/acp-18-110412018, 2018.
Stratton, R., Willet, M., Derbyshire, S., Wong, R., and Whitall, M.: Convection Schemes, Unified model documentation paper 027, Met Office, Exeter, UK, 2015.

Targino, A. C., Krejci, R., Noone, K. J., and Glantz, P.: Single particle analysis of ice crystal residuals observed in orographic wave clouds over Scandinavia during INTACC experiment, Atmos. Chem. Phys., 6, 1977-1990, https://doi.org/10.5194/acp-61977-2006, 2006.

Tobo, Y., Prenni, A. J., DeMott, P. J., Huffman, J. A., McCluskey, C. S., Tian, G., Pöhlker, C., Pöschl, U., and Kreidenweis, S. M.: Biological aerosol particles as a key determinant of ice nuclei populations in a forest ecosystem, J. Geophys. Res., 118, 10100 10110, https://doi.org/10.1002/jgrd.50801, 2013.

Vergara-Temprado, J., Miltenberger, A. K., Furtado, K., Grosvenor, D. P., Shipway, B. J., Hill, A. A., Wilkinson, J. M., Field, P. R., Murray, B. J., and Carslaw, K. S.: Strong control of Southern Ocean cloud reflectivity by icenucleating particles, P. Natl. Acad. Sci. USA, 115, 2687-2692, https://doi.org/10.1073/pnas.1721627115, 2018.

Vosper, S. B., Wells, H., Sinclair, J. A., and Sheridan, P. F.: A climatology of lee waves over the UK derived from model forecasts, Meteorol. Appl., 20, 466-481, https://doi.org/10.1002/met.1311, 2013.

Walters, D., Boutle, I., Brooks, M., Melvin, T., Stratton, R., Vosper, S., Wells, H., Williams, K., Wood, N., Allen, T., Bushell, A., Copsey, D., Earnshaw, P., Edwards, J., Gross, M., Hardiman, S., Harris, C., Heming, J., Klingaman, N., Levine, R., Manners, J., Martin, G., Milton, S., Mittermaier, M., Morcrette, C., Riddick, T., Roberts, M., Sanchez, C., Selwood, P., Stirling, A., Smith, C., Suri, D., Tennant, W., Vidale, P. L., Wilkinson, J., Willett, M., Woolnough, S., and Xavier, P.: The Met Office Unified Model Global Atmosphere 6.0/6.1 and JULES Global Land 6.0/6.1 configurations, Geosci. Model Dev., 10, 14871520, https://doi.org/10.5194/gmd-10-1487-2017, 2017.

Xiao, H., Yin, Y., Jin, L., Chen, Q., and Chen, J.: Simulation of the effects of aerosol on mixed-phase orographic clouds using the WRF model with a detailed bin microphysics scheme, J. Geophys. Res.-Atmos., 120, 8345-8358, https://doi.org/10.1002/2014JD022988, 2015.

Xue, L., Teller, A., Rasmussen, R., Geresdi, I., Pan, Z., and Liu, X.: Effects of Aerosol Solubility and Regeneration on Mixed-Phase Orographic Clouds and Precipitation, J. Atmos. Sci., 69, 1994 2010, https://doi.org/10.1175/JAS-D-11-098.1, 2012.

Zubler, E. M., Lohmann, U., Lüthi, D., Schär, C., and Muhlbauer, A.: Statistical Analysis of Aerosol Effects on Simulated MixedPhase Clouds and Precipitation in the Alps, J. Atmos. Sci., 68, 1474-1492, https://doi.org/10.1175/2011JAS3632.1, 2011. 